\title{
A Systematic Review of eHealth Interventions Addressing HIV/STI Prevention Among Men Who Have Sex With Men
}

\author{
Long Hoang Nguyen ${ }^{1,2} \cdot$ Bach Xuan Tran ${ }^{3,4} \cdot$ Luis E. C. Rocha ${ }^{5} \cdot$ Huong Lan Thi Nguyen ${ }^{6}$ Cui Yang ${ }^{4} \cdot$ Carl A. Latkin $^{4}$. \\ Anna Thorson ${ }^{1}$. Susanne Strömdahl ${ }^{1,7}$
}

Published online: 10 August 2019

○) Springer Science+Business Media, LLC, part of Springer Nature 2019

\begin{abstract}
A systematic review was conducted to summarize and appraise the eHealth interventions addressing HIV/STI prevention among men who have sex with men (MSM), and characterize features of successful eHealth interventions. Fifty-five articles (17 pilots and 38 full efficacy trials) were included with the predominance of web-based interventions in the United Statesbased settings. Intervention modalities include web-based, short message service (SMS)/text messges/email reminder, online video-based, computer-assisted, multimedia-based, social network, live chat and chat room, virtual simulation intervention, and smartphone applications. Forty-nine eHealth interventions achieved a short-term behaviour change among participants. Four studies were conducted with 12-month follow-ups; and only one of them could maintain the behaviour change over this longer time period which could be due to the lack of booster interventions. Our study suggests that eHealth interventions can achieve short term behaviour change among MSM, however limited interventions could maintain behaviour change over 12 months. Further eHealth intervention strategies to promote HIV prevention among MSM should be conducted and rigorously evaluated.
\end{abstract}

Keywords Systematic review $\cdot$ MSM $\cdot$ eHealth $\cdot$ Intervention $\cdot$ HIV $\cdot$ STI

\section{Introduction}

Electronic supplementary material The online version of this article (https://doi.org/10.1007/s10461-019-02626-1) contains supplementary material, which is available to authorized users.

Long Hoang Nguyen

hoang.nguyen@ki.se; longnh.ph@gmail.com

Bach Xuan Tran

bach.jhu@gmail.com

Luis E. C. Rocha

luis.rocha@gre.ac.uk

Huong Lan Thi Nguyen

huong.ighi@gmail.com

Cui Yang

cyang29@jhu.edu

Carl A. Latkin

Carl.Latkin@jhu.edu

Anna Thorson

anna.thorson@ki.se

Susanne Strömdahl

susanne.stromdahl@medsci.uu.se; susanne.stromdahl@ki.se
Men who have sex with men (MSM) are facing specific health needs [1-7]. An important health challenge among MSM is HIV/AIDS. Despite substantial advances in testing,

1 Department of Public Health Sciences, Karolinska Institutet, Stockholm, Sweden

2 Center of Excellence in Behavioral Medicine, Nguyen Tat Thanh University, Ho Chi Minh City, Vietnam

3 Department of Health Economics, Institute for Preventive Medicine and Public Health, Hanoi Medical University, Hanoi, Vietnam

4 Department of Health, Behaviours and Society, Johns Hopkins Bloomberg School of Public Health, Baltimore, MD, USA

5 Centre for Business Network Analysis, Business School, University of Greenwich, London, UK

6 Institute for Global Health Innovations, Duy Tan University, Da Nang, Vietnam

7 Section of Infectious Diseases, Department of Medical Sciences, Uppsala University, Uppsala, Sweden 
prevention and treatment, the overall trend of HIV incidence among MSM has been consistently upwards in most countries where data are accessible [2, 8,9]. Additionally, data reveal that MSM are at increased risk of sexually transmitted infections (STIs) and certain related cancers [1, 10-13]. Furthermore, MSM have been reported to be at a significantly higher risk of psychological distress in comparison with the general population, which is suggested to be due to their experiences of discrimination, stigma and isolation in the community $[2,4,5,14]$.

Despite higher rates of HIV/STIs, risk behaviours are frequently observed in MSM population. In the United States, Canada and England, the rates of unprotected anal intercourse (UAI) among MSM range from 13 to 42\% [15-17]. Likewise, a meta-analysis found that $30-84 \%$ MSM in Asian countries had UAI [18]. A recent study of Global Forum on MSM and HIV suggested that in limited-resource countries, condoms, lubricants and HIV testing services could be accessible to only $31 \%, 8 \%$ and $32 \%$ of MSM. respectively [19]. Moreover, MSM in many countries are more likely than heterosexual men to experience substance use disorders for tobacco, alcohol and illicit drugs [2, 20, 21].

Given the burden of diseases and risk behaviours among MSM, substantial efforts have been carried out to address unmet health needs. For instance, in some countries and regions, specific HIV/STI prevention and care guidelines for MSM have been published [22-25]. In addition, tailored interventions have been developed with an integrated approach that combines biomedical, behavioural and social perspectives to promote the positive changes of behaviours and reduce the risk of HIV/STIs among MSM [26]. However, insufficient resources, criminalization and stigma of same sex practices, lack of MSM-related organizations and lack of trained health care workers are major obstacles [27], requiring a novel approach that can address these limitations and strengthen the success of existing strategies.

Recently, interventions using eHealth approach have been proposed to overcome some of these obstacles [26-29]. This approach uses the Internet and cell phone technology to deliver health interventions or improve health services [30]. EHealth interventions can be delivered via diverse online tools such as emails, websites, videos, short message services (SMS), chat rooms, social networking sites or games. These methodologies benefit from being able to deliver messages at the time and place chosen by the users. EHealth interventions can also be implemented at a large scale with lower costs [28]. The success of eHealth interventions in changing risk behaviour, self-efficacy, knowledge, and clinical outcomes has been well-documented on various topics such as nutrition, smoking cessation, drinking alcohol and obesity prevention [31-33]. For MSM, eHealth interventions can increase the accessibility of the interventions as they can be accessed from all places where the Internet is available. Moreover, as MSM in many settings are a stigmatized population, measures to protect privacy, security and safety are of most importance. EHealth interventions offers a way to provide the intervention conveniently to the user regarding time and place, and can achieve a high sense of confidentiality $[34,35]$.

Previously, Schnall et al. (2014) and Strömdahl et al. (2015) published their systematic reviews and concluded that eHealth interventions had potential short-term effects on reducing risk behaviours and improving testing uptake. Additionally, more long-term follow-ups with larger sample size are required to assess the outcomes and impacts more comprehensively [34, 35]. However, the second study only reviewed eHealth trials in Europe countries [34]. Meanwhile, in recent years, since the fast growth of eHealth interventions in HIV/AIDS prevention and treatment has been observed [28, 36-38], it is expected to see an explosive number of eHealth interventions in MSM population, which may be far more than 13 interventions reviewed in the first study [35]. Therefore, it is necessary to update and extend prior reviews to inform the effectiveness of global eHealth interventions among MSM.

The aim of this review was to summarize and appraise the existing eHealth interventions related to HIV/STI prevention among MSM. In addition, this study identified and summarized considerations of eHealth intervention implementation in order to sustain effectiveness over time among MSM populations.

\section{Methods}

The PRISMA (Preferred Reporting Items for Systematic Reviews and Meta-Analyses) guideline informed the structure of this review [39].

\section{Inclusion and Exclusion Criteria}

The term "Men who have Sex with Men" (MSM) used in this review was defined as men who have sex with other men regardless of sexual identities (e.g. gay, bisexual, straight, etc.) $[34,40]$. We excluded transgender men and women because these populations may need targeted interventions as they are facing another epidemic scenario with considerably higher HIV risk compared to other subgroups of MSM [34, 40-42].

In this study, we employed the Population, Intervention, Comparison, Outcome (PICO) framework to guide the inclusion criteria and the search strategy [43]. The target "Population" of this review was adult MSM as defined above. The "Intervention" was eHealth-based pre-post interventions (without comparison groups), quasi-experimental studies (with comparison groups but no random assignment) or 
randomized controlled trials (RCT) (with comparison groups and random assignment). We included all "Outcomes" regarding biological markers and self-reported diagnoses of HIV/STIs, self-reported behavioural outcomes (HIV-related knowledge, condom use, unprotected sexual behaviour, substance use, condom use self-efficacy, HIV status disclosure etc.) and stigmatization (shame, internalized homonegativity, stigma, etc.). Studies published in peer-reviewed scientific journals with English language until 1 June 2019 were included. Non-peer reviewed documents were excluded but they were used to guide potential literature for the review.

Studies were excluded if they (1) used eHealth tools (email, website, etc.) only for data collection or sample recruitment; (2) were not peer-reviewed academic articles such as conference abstracts, news, magazine, letter, commentary, etc.; (3) were secondary data analysis; (4) were not available in English; (5) did not measure any HIV/AIDSrelated prevention outcomes; and (5) were narrative reviews, systematic reviews or meta-analysis.

\section{Identification of Studies}

The electronic databases including MEDLINE/Pubmed, PsycINFO, Embase and Cochrane Library were used to search the research articles that were published through 1 June 2019. An inclusive search strategy was developed. These search terms were adopted from prior reviews and developed with the support from senior authors and separated into three components: (1) Men who have sex with men; (2) mode of eHealth interventions; and (3) study designs. The Boolean phases such as "AND" and "OR" were used between and within groups, respectively. The search terms and search strategies for all database are listed in Supplementary 1. In addition, reference lists of articles retrieved and prior relevant systematic reviews were also searched for additional articles according to the inclusion and exclusion criteria [34, 35].

\section{Study Selection}

The search results from online databases were imported into Endnote X9 software. Duplications were removed $(n=794)$. Two researchers independently screened titles to meet inclusion criteria, and when in doubt, the full abstracts were reviewed $(n=1841)$. After that, the included articles were retrieved $(n=71)$ and appraised separately by two researchers, and 17 articles were removed according to exclusion criteria. A total of 54 articles were included in the final review. These articles were divided into two groups: pilot interventions and efficacy intervenitons. An intervention was classified as a pilot intervention if (1) it was clearly mentioned in the article as a pilot study, or (2) it was cited in other articles as a pilot intervention. Otherwise, this study was categorized as an efficacy intervention. A high agreement (90\%) was achieved between two reviewers. Differences between these authors were recognized and discussed with senior researchers to identify the appropriate solution.

\section{Study Quality Assessment}

We used the Integrated quality criteria for review of multiple study designs (ICROMS) to measure the quality of each study included in this review [44]. This tool has two components: (1) a scoring system for a number of quality criteria that are applicable for all study designs as well as particular for each study design (e.g., RCTs, qualitative studies, or cohort studies); and (2) a "decision matrix" revealing a minimum score for the quality of each study design, which are used to ensure the robustness of the study. ICROMS contains seven sections: (1) clear aims and justification, (2) bias in sampling, (3) outcome measurements and blinding, (4) follow-up, (5) other study aspects, (6) analytical rigour, and (7) reporting/ethical or other considerations. These sections have a total of 8 criteria which are applicable for all study designs; seven specfic criteria for RCTs; six specific criteria for pre-post studies; and five specific criteria for quasiexperimental studies. Each criterion is scored from 0 to 2 ( $2=$ criterion met; $1=$ unclear; $0=$ criterion not met $)$ [44]. This measure was applied in the previous eHealth review [45].

\section{Data extraction, Synthesis and Analysis}

A structured data extraction form was developed, piloted and revised. Data extraction included: study information, study design, subjects, sample sizes, types of intervention (web-based, video-based, mobile phone-based, etc.), applied behavioural theories, length of follow-up, short description of intervention, outcomes (e.g., sexual risk behaviours for HIV/STI, rate of STIs treatment, etc.), and main results of interventions (e.g., reducing sexual risk behaviours, increasing HIV/STIs testing uptake and condom use, etc.). In each study, we also extracted author recommendations (if available) for sustaining further ehealth intervention. The text of considerations was coded by two researchers and discussed among the research team until reaching the consensus. We used a similar discussion to aggregate the codes to different themes or sub-themes.

After data extraction, the two researchers compared their data extraction results and found an agreement on $90 \%$. Data extraction for study information, subjects and sample sizes achieved the highest agreement (100\%), while information about author recommendations had the lowest agreement $(80 \%)$. Differences were discussed with the senior researchers and resolved. Spearman's correlation rh0 was estimated 
to identify the correlation between lengths of follow-up and retention rates.

\section{Results}

Figure 1 illustrates the overall results of the searching process. After searching and screening, a total of 55 studies were yielded, which were published between 2007 and 1 June 2019.

Table 1 indicates major characteristics of the studies included in the final review regarding types of study (pilot or efficacy trials). Most of the studies were efficacy trials ( $n=38$ studies). Randomized controlled trials (RCT) were a primary design ( $\mathrm{n}=37$ studies), following by pre-post interventions ( $\mathrm{n}=12$ studies) and quasi-experimental designs ( $n=6$ studies). The majority of studies were conducted in the
United States ( $\mathrm{n}=36$ studies) and Asia and Australia regions ( $n=13$ studies), whereas no study was found in Africa. Most of studies were performed among general MSM ( $n=42$ studies), following by rural MSM ( $\mathrm{n}=2$ studies), black MSM ( $\mathrm{n}=2$ studies), methamphetamine-using MSM ( $\mathrm{n}=2$ studies), young MSM ( $n=4$ studies) and HIV + MSM ( $n=3$ studies). Only two interventions reported using booster interventions. Web-based was the dominant eHealth platform ( $n=22$ studies), following by SMS/Email/Text/Voice messages $(n=9$ studies $)$ and Video $(n=7$ studies $)$.

Figure 2 illustrated the trend of ehealth intervention according to the main eHealth modes. From only seven interventions in 2007-2010, the number of trials doubled in 2011-2014 ( $\mathrm{n}=13$ studies) and were approximately 2.6 times higher in the period 2015-2019 ( $\mathrm{n}=35$ studies). The volume of Web-based, Video-based, and SMS/Email/ Text/Voice message-based interventions had the most rapid
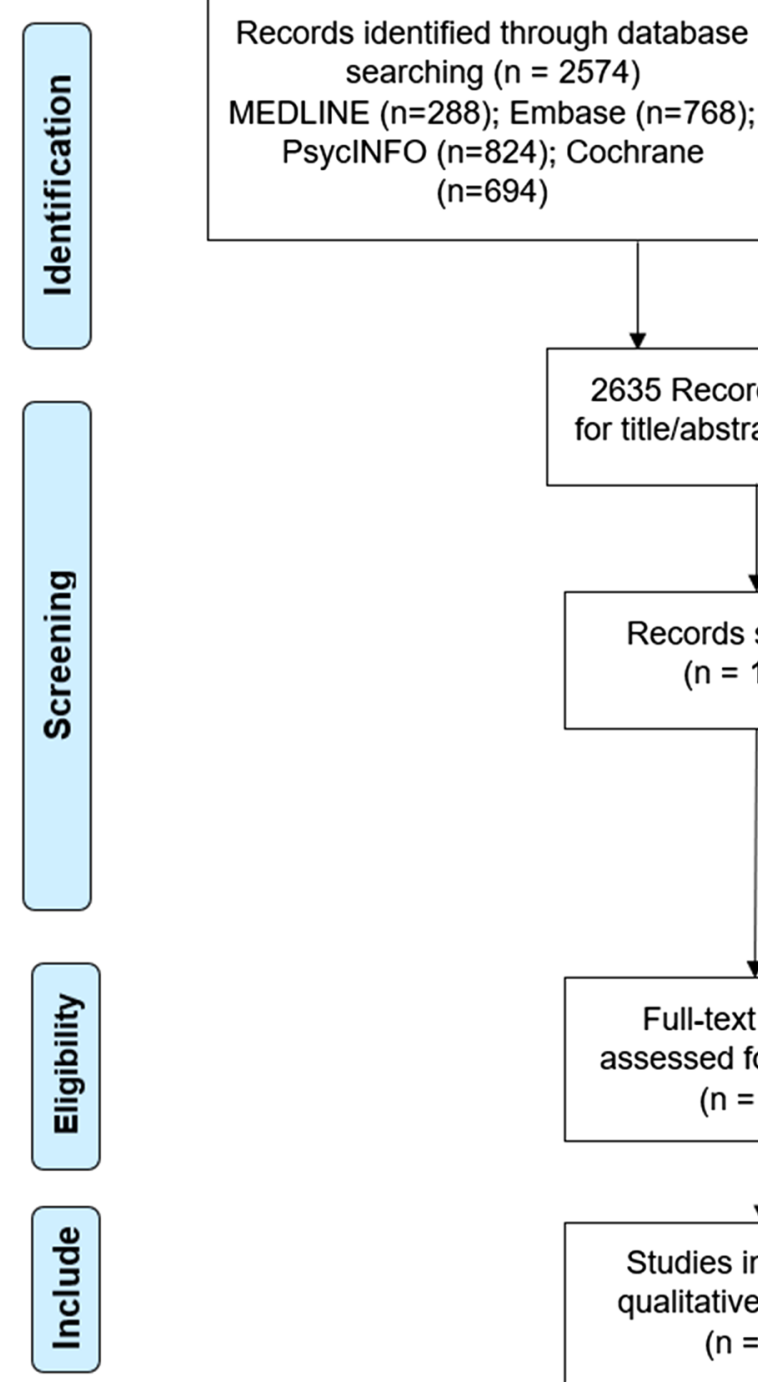

Additional records identified through other sources $(n=61)$

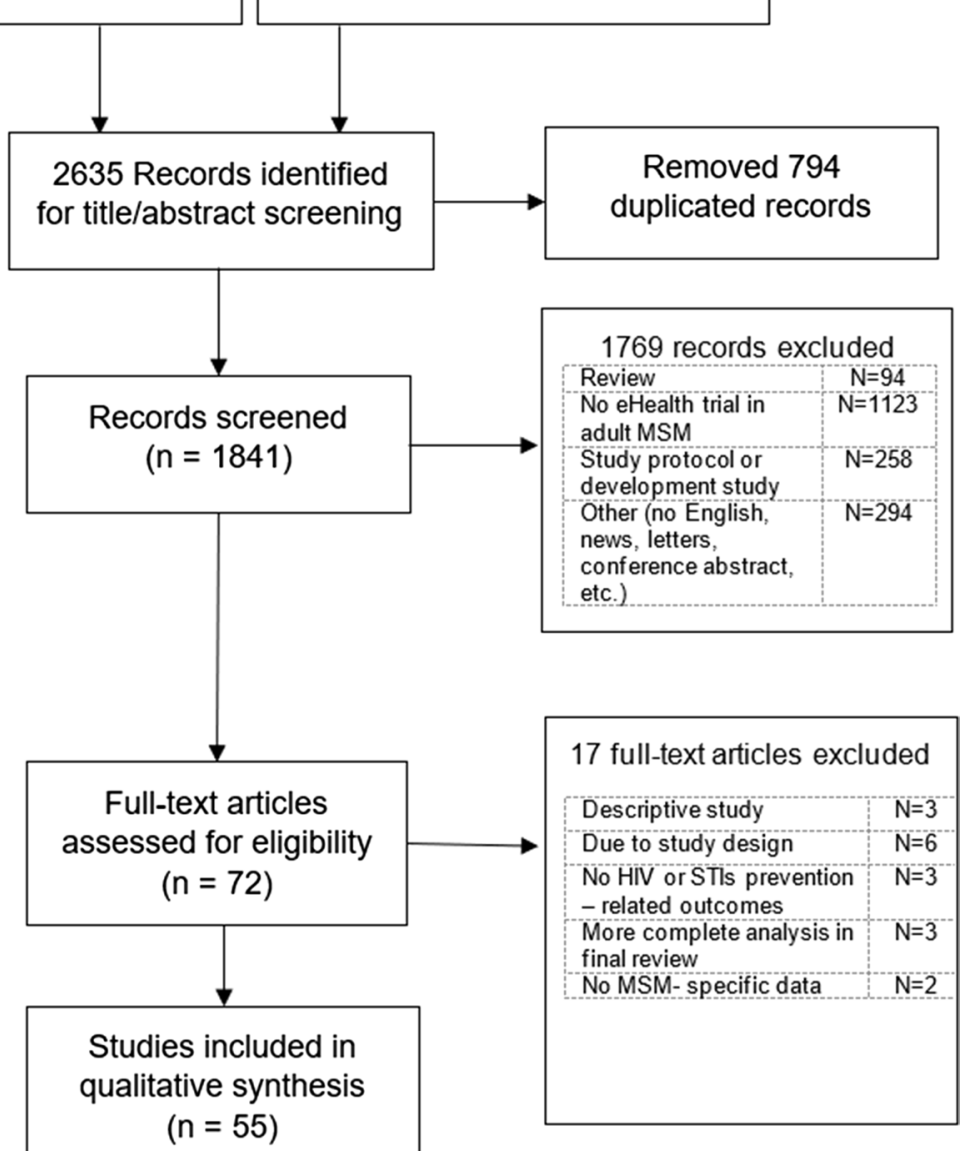

Fig. 1 Flow chart of searching and screening process 
Table 1 Characteristics of included studies $(n=55)$

\begin{tabular}{|c|c|c|c|c|c|c|}
\hline \multirow[t]{2}{*}{ Characteristics } & \multicolumn{2}{|c|}{ Total } & \multicolumn{2}{|c|}{ Pilot trials } & \multicolumn{2}{|c|}{$\begin{array}{l}\text { Efficacy } \\
\text { trials }\end{array}$} \\
\hline & $\mathrm{N}$ & $\%$ & $\mathrm{~N}$ & $\%$ & $\mathrm{~N}$ & $\%$ \\
\hline Total & 55 & 100.0 & 17 & 30.9 & 38 & 69.1 \\
\hline \multicolumn{7}{|l|}{ Study designs } \\
\hline RCT & 37 & 67.3 & 10 & 58.8 & 27 & 71.0 \\
\hline Quasi-experiment & 6 & 10.9 & 0 & 0.0 & 6 & 15.8 \\
\hline Pre-post design & 12 & 21.8 & 7 & 41.2 & 5 & 13.2 \\
\hline Duration of follow-up (months) & & & & & & 0.0 \\
\hline$\leq 1$ months & 10 & 18.2 & 5 & 29.4 & 5 & 13.2 \\
\hline$>1-3$ months & 17 & 30.8 & 6 & 35.3 & 11 & 28.9 \\
\hline$>3-6$ months & 15 & 27.3 & 5 & 29.4 & 10 & 26.3 \\
\hline$>6-12$ months & 10 & 18.2 & 1 & 5.9 & 9 & 23.7 \\
\hline No report & 3 & 5.5 & 0 & 0.0 & 3 & 7.9 \\
\hline \multicolumn{7}{|l|}{ Main eHealth modes } \\
\hline Website & 22 & 40.0 & 6 & 35.3 & 16 & 42.1 \\
\hline SMS/email/text/voice messages & 9 & 16.4 & 3 & 17.6 & 6 & 15.8 \\
\hline Video & 7 & 12.6 & 2 & 11.8 & 5 & 13.2 \\
\hline Computer-assisted & 3 & 5.5 & 0 & 0.0 & 3 & 7.9 \\
\hline Multimedia & 2 & 3.6 & 1 & 5.9 & 1 & 2.6 \\
\hline Live chat and chat room & 3 & 5.5 & 2 & 11.8 & 1 & 2.6 \\
\hline Virtual simulation & 1 & 1.8 & 0 & 0.0 & 1 & 2.6 \\
\hline Online social network & 5 & 9.1 & 0 & 0.0 & 5 & 13.2 \\
\hline Smartphone applications & 3 & 5.5 & 3 & 17.6 & 0 & 0.0 \\
\hline \multicolumn{7}{|l|}{ Settings } \\
\hline United States & 36 & 65.5 & 15 & 88.2 & 21 & 55.3 \\
\hline Canada and Latin America & 3 & 5.5 & 0 & 0.0 & 3 & 7.9 \\
\hline Europe & 3 & 5.5 & 0 & 0.0 & 3 & 7.9 \\
\hline Asia and Australia & 13 & 23.5 & 2 & 11.8 & 11 & 28.9 \\
\hline \multicolumn{7}{|l|}{ Population } \\
\hline General MSM & 42 & 76.4 & 13 & 76.4 & 29 & 76.3 \\
\hline Young MSM & 4 & 7.3 & 2 & 11.8 & 2 & 5.3 \\
\hline Rural MSM & 2 & 3.6 & 1 & 5.9 & 1 & 2.6 \\
\hline Black MSM & 2 & 3.6 & 0 & 0.0 & 2 & 5.3 \\
\hline $\mathrm{HIV}+\mathrm{MSM}$ & 3 & 5.5 & 0 & 0.0 & 3 & 7.9 \\
\hline Methaphetamin-using MSM & 2 & 3.6 & 1 & 5.9 & 1 & 2.6 \\
\hline \multicolumn{7}{|l|}{ Major primary outcomes } \\
\hline Sexual risk behaviors & 33 & 60.0 & 10 & 58.8 & 23 & 60.5 \\
\hline HIV/STI testing and self-testing & 19 & 34.5 & 5 & 29.4 & 14 & 36.8 \\
\hline HIV/STI disclosure, stigma, and internalized homonegativity & 9 & 16.4 & 1 & 5.9 & 8 & 21.1 \\
\hline HIV/STI knowledge and attitudes & 8 & 14.5 & 1 & 5.9 & 7 & 18.4 \\
\hline Self-efficacy & 7 & 12.7 & 3 & 17.6 & 4 & 10.5 \\
\hline $\begin{array}{l}\text { Others (quality of life, pre-exposure prophylaxis undertaking, } \\
\text { substance use, etc.) }\end{array}$ & 21 & 38.2 & 9 & 52.9 & 12 & 31.6 \\
\hline \multicolumn{7}{|l|}{ Behavioral theory use } \\
\hline None & 21 & 38.2 & 5 & 29.4 & 16 & 42.1 \\
\hline Single theory & 18 & 32.7 & 8 & 47.1 & 10 & 26.3 \\
\hline Multiple theories & 16 & 29.1 & 4 & 23.5 & 12 & 31.6 \\
\hline \multicolumn{7}{|l|}{ Booster intervention } \\
\hline No & 53 & 96.4 & 16 & 94.1 & 37 & 97.4 \\
\hline Yes & 2 & 3.6 & 1 & 5.9 & 1 & 2.6 \\
\hline
\end{tabular}


Fig. 2 Trend of eHealth interventions overtime

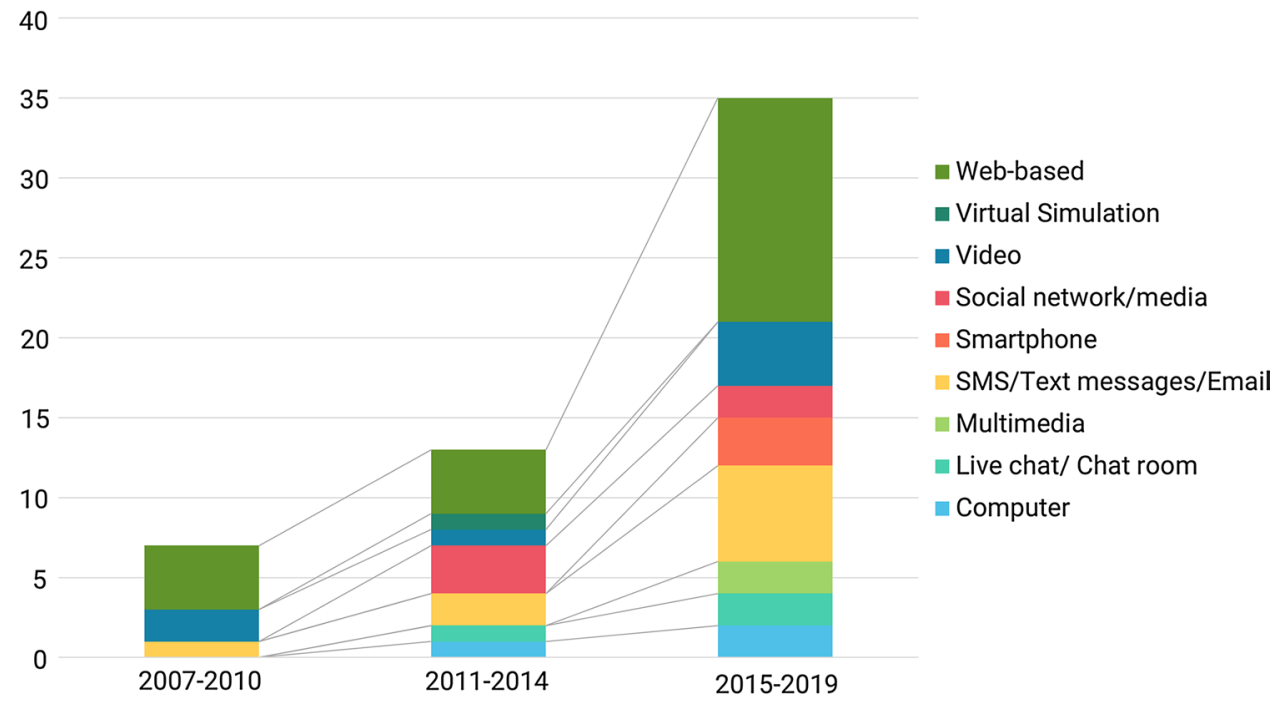

increase from 2007 to 2019 compared with other modes. Notably, despite an availability of virtual simulation-based intervention in 2011-2014, this method was not considered for the ehealth intervention in the next period. Otherwise, interventions using smartphone applications were piloted as a new approach in the duration 2015-2019 ( $\mathrm{n}=3$ studies).

\section{Characteristics of Selected Studies}

The features of each paper regarding study design (length of follow-up, sample size, retention rate), eHealth strategies, theoretical framework, intervention, main outcomes and results were described in Supplementary 2.

\section{Population and Sample Size}

All studies targeted MSM in accordance with the inclusion criteria. Several studies focused on specific parts of the MSM population such as rural MSM [46, 47], black MSM [48, 49], methamphetamine-using MSM [50, 51], HIV + MSM [52-54] and young MSM [55-58]. Study sample size ranged from 41 [59] to 3092 men [60]. Twentytwo studies used online sources (e.g., websites, forums, or chatrooms), 12 studies used offline sources (e.g., clinics or organizations), and 19 studies used both sources for recruitment.

\section{Length of Follow-Up and Retention Rate}

The length of follow-up ranged from immediate after intervention [61] to 12 months $[49,58,62-64]$ with the average retention rate of $79.8 \%$ (ranging from 46.0 [65] to $100 \%$ [66-69]). Four studies measured pre and post-evaluations in different participants [70-73]. There did not seem to be a relationship between retention rates and length of follow-ups
(Spearman's rho $=0.047, p=0.75)$ (Fig. 3). For instance, the retention rate of Schonnesson et al.'s intervention implemented among Swedish MSM was only $51.8 \%$ although the duration of follow-up was 1 month [74]. No intervention mentioned the washout effect (or washout period, i.e. the period between two interventions or two sessions of intervention that no active intervention is given to the intervention group [75]).

\section{Theoretical Framework}

Most of the studies $(n=34)$ applied behavioural theories as the theoretical framework of the interventions. Meanwhile, 21 studies did not mention or were not guided by any behavioural theories. The most common theory used was Information-Motivation-Behavioural skill (IMB), which was available in nine studies $[46,48,53,54,58,59,68,74$, 76], followed by Social Cognitive Theory [50, 51, 53, 62, 73, 77, 78], Stages of Change Theory [62, 69, 79], and HealthBelief Model [51, 69, 80]. Other behavioural theories used included Sexual Health Model [81], Social Support Theory [50], Social Learning Theory [60], Theory of Planned Behaviour [77], Theory of Reasoned Action [49], Self-efficacy Theory [52], Diffusion of Innovation Theory [71], Selfdetermination Theory [55], Natural Helper [73], Empowerment Theory [72, 82], Community Mobilization Model [70], Popular Opinion Leader Model [71], Protection-Motivation Theory [83], Integrated Behavioural Model [55, 84], Protection-Motivation Theory [85], Dual Processing CognitiveEmotional Decision Making Framework [57], Prospect Theory, Common Ingroup Identity Model, and Social Identity Theory [65]. Sixteen interventions were guided by multiple theories. For example, Hightow-Weidmen et al. (2019) conducted a web-based RCT called HealthMpowerment.org that incorporated Theory of Planned Behaviour, Theory of 
Fig. 3 Mean retention rates by different duration of follow-ups

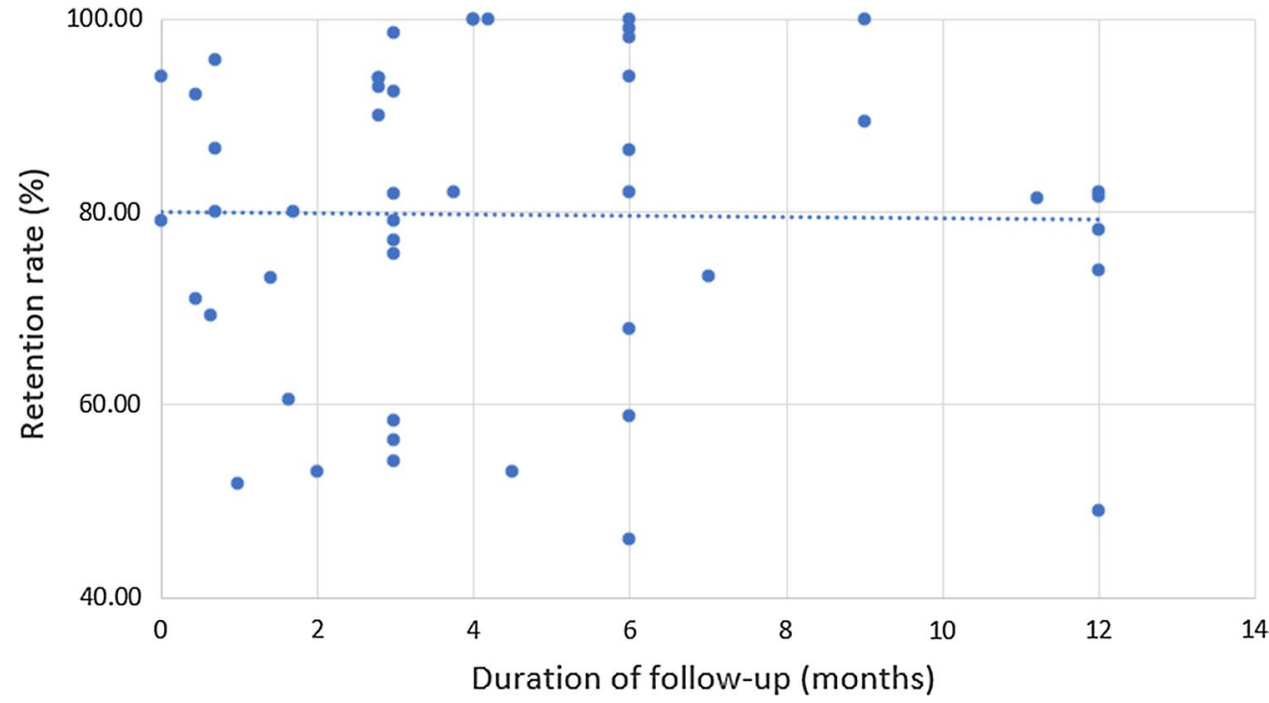

Reasoned Action, Self-efficacy Theory, Social Cognitive Theory and Health Belief Model in order to decrease sexual risk behaviours and increase condom use [49]. The use of behavioural theories varied across studies. For instance, Rhodes et al. applied the Natural Helper Model, Social Cognitive Theory, and Empowerment education model in training the interventionist [73]. Another intervention conducted by Reback et al. (2012) used the Social Support Theory, Social Cognitive Theory and Health Belief Model to develop tailored social support and health education messages for participants [50].

\section{Outcomes}

Sexual risk behaviors were the most common primary outcomes $(n=32$ studies), following by HIV/STI testing and self-testing ( $\mathrm{n}=18$ studies) and HIV/STI disclosure, stigma, self-esteem, and internalized homonegativity ( $\mathrm{n}=9$ studies). Several studies focused on HIV/STI prevention knowledge and attitudes [47, 56, 67, 86, 87], HIV disclosure [60, 62, 79, 87-89], gonorrhea and chlamydial infection and treatment [90], or pre-exposure prophylaxis uptake [57, 91] and adherence [92, 93]. Reback et al. (2012) had an additional outcome regarding the frequency of methamphetamine use among MSM [50], and Hightow-Weidman et al. (2019) investigated the intention to use a condom, attitudes toward safe sexual behaviours, condom use self-efficacy, depressive symptoms, social support and social isolation [49]. Other outcomes of interest included level of internalized homonegativity among MSM $[61,94]$, initiation of antiretroviral therapy (ART) among HIV + MSM [89], shame-related sexual stigma [77], health-related quality of life [52], HBV vaccination [63], Human Papillomavirus (HPV) vaccination knowledge, attitudes and beliefs [83], or HPV vaccine initiation and completion [85], and HIV-related self-efficacy $[52,55]$.

\section{Intervention Characteristics and Outcomes}

\section{Web-Based Intervention $(n=22)$}

Most of the studies used a Website platform for the intervention $(\mathrm{n}=22)$. RCTs were the predominant study design $(\mathrm{n}=17)$ [47-49, 52, 55, 58, 61, 62, 74, 76, 81, 83, 85, 90, $91,94,95]$, following by pre-post intervention $(n=4)[46$, $56,67,70]$ and quasi-experiment $(n=1)$ [89].

In terms of pilot trials, Bowen et al. performed one webbased pilot RCT [47], using the Social Cognitive Theory to develop two 20-min modules about encountering sexual risk behaviors and risk of HIV infection [47]. The authors found positive changes in the primary outcomes including HIV/ AIDS knowledge and self-efficacy of MSM [47]. Another pilot trial used the Self-determination theory and Integrated Behavioural model to develop tailored website for young MSM that was customized based on MSM's characteristics [55]. The intervention successfully increased HIV/AIDS testing and self-efficacy in young MSM [55]. In addition, one pilot intervention used the Protection-Motivation Theory to develop a tailored website so-called "Outsmart HPV", which informed knowledge about HPV and HPV vaccination for the intervention group $[83,85]$. Meanwhile, the control group received only a website with the standard information. Post-evaluation revealed better perceived risk of anal cancer, self-efficacy, perceived harms of vaccine and intentions to get vaccinated, as well as HPV vaccine initiation and completion in the intervention arm compared with the control arm $[83,85]$.

Two recent web-based pilot RCTs were conducted by Clark et al. to test partner notification for syphilis diagnosis 
[95], and by Wray et al. to examine trial's effectiveness in reducing alcohol use problem and sexual risk behaviors [91]. The first trial employed a web-based partner notification with or without referral cards, which informed available testing and treatment resources for syphilis testing [95]. Meanwhile, the second trial offered a personalized and interactive web application so-called "Game plan" and standard post-evaluation counseling [91]. As compared to the control group (receiving only standard of care), both studies successfully achieved preferable outcomes in the intervention group, including higher likelihood of notifying sex partners (odds ratio, $\mathrm{OR}=2.18,95 \%$ CI $1.30-3.66 ; \mathrm{p}=0.003$ ) in the former study [95], or significant reduction of alcohol use (risk ratio, $\mathrm{RR}=0.83, \mathrm{p}=0.047$ ) and number of sex partners $(\mathrm{RR}=0.50, \mathrm{p}<0.001)$ in the latter intervention [91].

Regarding efficacy trials, the first intervention was a webbased pre-post experiement conducted by Bowen et al. on MSM living in rural areas [46]. This study provided three 20-min modules about "Knowledge", "Partner" and "Context of Risk", which were based on the IMB theoretical model [46]. The intervention showed significant improvements of sexual risk behaviors (increase condom use and decrease number of sex partners) among rural MSM [46].

For black MSM, Hightow-Weidman et al. (2019) conducted a web-based RCT called HealthMpowerment.org among 474 black MSM [49]. This intervention group participated in live chats with experts, interactive quizzes, individualized health, "hook up/sex" journals and decision support tools, while the control group received only general HIV/ STI information. Authors found that the intervention could reduce $32 \%$ risk of condomless anal intercourse $(\mathrm{RR}=0.68$, $95 \%$ CI $0.43,0.93$ ) but this outcome was not maintained after 12 months [49]. Another RTC was perfomed in black MSM by Fernandez et al., where the intervention group was provided a tailored website and live chat to interact with, motivate, reinforce and challenge the participants. The IMB model was used to build the intervention content. Findings suggested lower odds of sexual risk behaviors in the intervention group ( $\mathrm{OR}=0.55, \mathrm{p}=0.020)$ [48].

Young MSM were the target population in one pre-post intervention [56], and one RCT [58]. The former study offered tailored web-based education modules to promote health behavior changes; however, the authors did not inform any theoretical framework [56]. The second study used IMB framework to provide an individualized web-based education (7 modules about risk behavior changes) for the intervention group and general HIV prevention knowledge for the control group [58]. Moreover, this study used booster sessions at month 3 and month 6 . Both interventions obtained the improvement of HIV/AIDS knowledge and sexual risk behaviors [56], and reduced rates of STIs compared with the control group [58]. In addition, the second intervention could reduce $40 \%$ risk of gonorrhea or chlamydia infections at month 12 for intervention group $(\mathrm{RR}=0.60,95 \% \mathrm{CI}$ $0.38-0.95, \mathrm{p}=0.01)$ and $17 \%$ risk of condomless anal sex (prevalence ratio $=0.83,95 \% \mathrm{CI} 0.70,0.99, \mathrm{p}=0.04$ ) than the control arm [58].

Among other studies, Carpenter et al. [76] and Schonnesson et al. [74] shared similar theoretical framework as they used the IMB for constructing the interventions. Carpenter et al. provided seven modules containing interactive educational and motivational exercises, and skill training sessions [76]. Meanwhile, Schonnesson et al. constructed three modules (Information module, Motivation module and Behavior module), with two interactive sessions and feedback in each module [74]. The findings of these two interventions indicated significant improvement in sexual risk behaviors [74, 76], HIV knowledge [74] and motivation in using condom [74].

Stigma and internalized homonegativity were primary outcomes of interventions implemented by Adam et al. [70], Lin et al. [61] and Fleming et al. [94]. Adam et al. accessed a website hivstigma.com, and recruited eight moderators to facilitate discussions about stigma toward MSM on this website. The Community Mobilization model was applied. Results found significant reduction of stigma-related attitudes and behaviors among members of websites [70]. Lin et al. developed three interactive web-based modules to raise the awareness about same sex practices and misconception about MSM. The authors found that participants who engaged more in the intervention had lower level of internalized homonegativity [61]. Otherwise, Fleming et al. used the Evaluative Conditioning technique in three intervention groups to increase (1) self-esteem (group 1); (2) positive gay sexual-related attitudes (group 2); and (3) both (group 3 ), while the control group received only neutral evaluative conditioning sessions [94]. However, the authors found no diffence between intervention groups and control group regarding self-esteem and internalized homonegativity [94].

\section{SMS, Text/Voices Messages and Email-Based Intervention $(n=9)$}

Four SMS-based interventions were performed using prepost $[50,92](n=2)$ and quasi-experimental designs [63, $66](n=2)$.

Regarding pilot intervention, Reback et al. [50] designed SMS reminder systems in their pre-post intervention that could be tailored to MSM based on their sexual risk behaviours for HIV/STIs. The SMS reminders achieved a statistically significant decrease of methamphetamine use and sexual risk behaviours for HIV/STIs compared to the baseline. Notably, the authors developed personalized messages based on several behavioural theories, which possibly enhanced the effectiveness of the intervention [50]. Another SMS and email-based pre-post pilot intervention 
was conducted by Fuchs et al. [92], offering iText—a system delivering interactive check-in SMS and emails weekly to remind PrEP adherence. Authors reported significant reductions of missed doses at 50\% $(p=0.008]$ and $77 \%(p=0.007)$ when comparing self-reported missed days and pill counts at quarterly visits before and after intervention [92]. In India, a pilot RCT conducted by Mimiaga et al. [82] using text/voice messages via mobile phone to encourage male sex workers using condom during sexual encounters. The authors applied the Empowerment Theory to develop the tailored-messages, resulting in significantly higher rate of condom use among MSM in intervention arm compared to control arm after 3 months follow-up [82].

For efficacy trials, Bourne et al. [66] in their quasiexperiement provided tailored SMS based on MSM' risk behaviors and found a remarkable enhancement in HIV/ STI re-testing rates in the intervention group that that in the control group ( $64 \%$ vs. $30 \%$, OR $=4.4, p<0.001)$. Reback et al. performed another study using RCT design to test the effect of theory-driven text messages in decreasing the use of methamphetamine in MSM [51]. The Social Support Theory, Social Cognitive Theory, and Health Belief Model were used to develop the messages. By offering interactive theory-based messages along with support of peer health educators, the intervention reduced significantly the rate of condomless anal sex with main partners, but did not observe the difference in methamphetamine-related outcomes (e.g. methamphetamine use or sex on methamphetamine) between intervention and control groups [51]. Similarly, the SMSbased intervention conducted by Mclver et al. found no statistically significant change on rates of completion of second and third doses of HBV vaccination among MSM [63]. The authors suggested possible reasons might include a lack of tailored educational messages and automated reminder system for clinicians [63].

In the USA, Moore et al. provided iTab-an individualized text message-based RCT-to MSM for supporting adherence in PrEP uptake [93]. The intervention group had more likelihood to reach near-perfect adherence compared with the control group $(\mathrm{OR}=1.56,95 \%$ CI $1.00-2.42$, $\mathrm{p}<0.05$ ), while no improvement was found in minimally adequate adherence in both arms [93]. In Australia, another RCT offering SMS reminder, coupled with postal homecollection kits, successfully increased the rate of chlamydia retesting among MSM [96]. In Hong Kong, an email-based RCT conducted by Lau et al. (2008) [86], where MSM in the intervention group received HIV/STI prevention educational emails every 2 weeks. In addition, peer counsellors provided counselling via different means (chat rooms, email, gay website, etc.) to the participants twice a month. However, the intervention group did not report a statistically significant improvement regarding HIV/STI-knowledge, self-reported STI rates and consistent condom use compared to the control group [86]. The retention rate was $59 \%$, which could have introduced bias. In addition, this intervention did not indicate any behavioural theories guiding their email-based intervention [86].

\section{Video-Based Intervention $(\mathrm{n}=7)$}

Seven trials, six RCTs [60, 69, 80, 97-99] and one pre-post experiment [88], used videos as the main modality of the intervention. Chiassonn et al. [88], in their pilot pre-post trial, designed nine-minute online videos so-called "The Morning After" to facilitate HIV disclosure, HIV testing, as well as reduce alcohol use and sexual risk behaviours for HIV/STIs. After 3-month follow-up, participants were more likely to report that they disclosed their HIV status to sexual partner before sex $(\mathrm{OR}=3.37, \mathrm{p}<0.001)$ and decreased number of sexual partners and frequency of sexual risk behaviours for HIV/STIs [88]. Furthermore, Stark et al. conducted a pilot RCT using communication training videos, along with couples HIV testing and counseling and a substance use module, to significantly reduce the drug use problems in the intervention group compared to the control group (received only couples HIV testing and counseling) at 3- and 6-month follow ups [99].

Regarding efficacy interventions, Hirshfield et al. applied the Social Learning Theory and strategies to provide dramatic and documentary videos with similar goals [60]. They found that after 2-month follow-up, the intervention group was more likely to disclose sero-status to their partners and reduce sexual risk behaviours for HIV/STI (compared to control group receiving only text messages) [60]. Blas et al.'s intervention, which was guided by the Health-Belief Model and the Transtheoretical model, provided 5-min videos to motivate MSM to get HIV testing while the control group only received text messages via gay website about this topic. No significant increase was observed among gay MSM; otherwise, in the sub-group of non-gay MSM $(n=97)$, a significant increase in the HIV test rate was seen compared to the control [69].

A study by Lau et al. involved a fear appeal approach in the videos, which communicated that STI/HIV transmission would negatively affect the inter-personal relationship [97]. The authors argued that fear associated with social bonds could impact more effectively than fear related to physical health. However, after 3 months follow-up, they found that the rate of sexual risk behaviours the intervention group was not statistically different compared to the control group who received only general HIV-related information on a website [97]. Two other RCTs conducted in China to promote HIV testing $[80,98]$ and sexual risk reduction [80]. While Tang et al.'s trial, without information about applied theory, found no significant difference between intervention and control groups in HIV testing rate [98], Wang et al.'s intervention, 
using the Health Belief Model, obtained significantly positive outcomes in increasing HIV testing and decreasing the number of sex partners in the intervention group compared to the control group [80].

\section{Computer-Assisted Intervention $(\mathrm{n}=3)$}

All three computer-assisted interventions are efficacy trials. Nostlinger et al.'s RCT [53] and Bachmann et al.'s prepost experiment [79]) employed a computer system to support providers in delivering tailored messages to MSM on safe sex. The first study used Transtheoretical model [79], the second study used Social Cognitive and InformationMotivation-Behavioural theories [53]. Both interventions reported a decline in sexual risk behaviours for HIV/STI after receiving five interventions and after 6-week follow-up, respectively [53, 79].

Meanwhile, Klein et al.'s quasi-experiment study concentrated on risk behaviours (substance use and sexual practices) reduction, inter-sectionalities, and HIV/STIs prevention knowledge and attitude among Black MSM [87]. This study applied the Social Cognitive theory alone [87]. None of significant differences were found between both intervention and control groups in terms of sexual risk behaviours. However, the authors reported a higher likelihood of intention in using condom and motivating HIV testing in the intervention group than that in the control group [87].

\section{Multimedia-Based Intervention $(n=2)$}

One multimedia-based pilot RCT was conducted by Solorio et al. in 2014, which aimed to facilitate HIV testing and condom use [84]. The authors used a number of communication tools such as radio, website, social media outreach, mobile phone reminder messages system, printed materials and hotline. No statistically significant change in condom use or HIV testing rate was observed after the intervention at 16 weeks follow-up. The authors suggest that uptake of the intervention might be low due to 1) changing the web site address during the intervention, and 2) existing stigma in the community which may hinder uptake of HIV testing [84].

Likewise, one efficacy trial performed by Prati et al. in Italy used mass media to deliver gain-framed messages, which underlined the merits of safe sexual practices and HIV testing, and various characters and slogans to generate a superordinate identity and change perceptions of general population, MSM and migrant people about HIV/AIDS. In this study, authors applied the Prospect Theory, Common Ingroup Identity Model, and Social Identity Theory to form the message. However, outcomes of this intervention were limited since participants were only likely to decrease unprotected sexual intercourses with partners having unknownHIV status, but not likely to reduce unprotected sexual intercourses with multiple partners as well as increase HIV testing ( $p>0.05)$ [65]. Authors claimed that mass media campain might positively affect general population but were not suitable for minority groups [65].

\section{Online Virtual Simulation Intervention $(n=1)$}

One innovative intervention designed by Christensen et al. was called the Socially Optimized Learning in Virtual Environments (SOLVE), using a virtual world to reflect the lives of MSM (at house party and night club) and simulating barriers associated with safe sex, condom use negotiation and refusing sex without condom [77]. The authors developed this trial based on the Theory of Planned Behaviour and Social cognitive theory. The program was expected to help MSM improve decision making skills in real life situations. The study reported no change in sexual risk behaviours after 3 months follow-up. However, the level of shame, which was a predictor of risk behavior reduction, was significantly diminished in the intervention group compared to the control group [77].

\section{Online Social Network Intervention $(n=5)$}

Among five efficacy interventions, three RTCs [100-102] and one quasi-experiment study [71] were performed through Facebook, when another RCT was conducted in four MSM-friendly social media sites including Adam4Adam, BlackGayChat, Craigslist, and Gay.com [72]. In 2010, Young et al. conducted a web-based peer leader intervention among 112 MSM in the United States and found that the intervention group requested more HIV testing kit than the control group after intervention; and increasing community cohesion was a positive predictor of increased HIV testing rates [100, 102]. Two years later, Young et al. performed a RCT in Peru including 556 MSM, reporting that the odds of getting an HIV test in the intervention group were 2.61 times higher than in the control group $(\mathrm{OR}=2.61 ; 95 \% \mathrm{CI}$ 1.55-4.38) [101].

Meanwhile, a quasi-experimental, non-equivalent control study conducted by Ko et al. (2013) recruited 1037 MSM to participate in an Internet-popular opinion leader (iPOL) intervention via Facebook [71]. In this intervention, MSM could create social networks, share and exchange news, video clips, reports, opinions and connect to other MSM. The study found that the intervention group reported significantly increased HIV testing rates and condom use rates after 6 months follow up in comparison with the control group that received no intervention [71].

The remaining intervention of Rhodes et al. provided individualized information about HIV testing to users of four social media sites, using the Empowerment, Social Cognitive and Natural Helping theories. The results indicated a 
significant increase in HIV testing rate among MSM in the intervention group $(\mathrm{OR}=2.9 ; 95 \% \mathrm{CI} 1.8-4.7)$ compared to control group [72].

\section{Live Chat and Chat Room ( $n=3)$}

Two pre-post pilot interventions utilized live chat and chat room to deliver intervention messages [59, 73]. A pilot prepost CyBER/testing trial designed by Rhodes et al. [73] applied the Natural Helper Model, Social Cognitive theory, Empowerment education and Ask-Advise-Assist model to train an interventionist. The interventionist participated in the chat room daily, posted topics about HIV, testing and prevention and answered questions. In addition, the interventionist could refer MSM to online videos on HIV testing experiences. After 6 months follow-up, a significant increase in HIV testing rate was observed among chatters $(44.5 \%$ at baseline to $60 \%$ at post-evaluation, $p<0.001$ ) [73]. Another pilot study was conducted by Lelutiu-Weinberger et al. on 41 MSM using live chat on Facebook to reduce sexual risk behaviours and substance use (alcohol and drug) [59]. The Information-Motivation-Behavioural theory was used to improve substance use, sexual risk behaviors, as well as motivation and personal responsibility. The number of days of substance use as well as sexual risk behaviours among MSM were significantly reduced at 3 months follow up [59]. Both studies emphasized the important role of interventionist/facilitators in the success of the intervention $[59,73]$.

One efficacy RCT was performed by Cruess et al. on 167 HIV + MSM in the United States [54]. The authors applied the IMB theory to build four sessions about online partner seeking and risk reduction of HIV transmission [54]. Each session contained three components including information, motivational skills and behavioral strategies, and one assignment was provided to the participants after finishing each session to maintain the effect of intervention [54]. Meanwhile, the control group also received other four sessions about topics that were not related to HIV/AIDS. After 6-month follow-up, the intervention arm decreased condomless anal sex (CAS) practices with serodiscordant partners (RR $=0.373 ; 95 \%$ CI: $0.207-0.672 ; p=0.001)$ but increased CAS with seroconcordant partners $(\mathrm{RR}=2.142$; 95\% CI: $1.268-3.617 ; \mathrm{p}=0.004)$ compared to the control group [54].

\section{Smartphone Applications $(\mathrm{n}=3)$}

Two studies using smartphone applications (apps) are pilot RCTs $[57,68]$, and one study was pilot pre-post experiment [78]. Bauermeister et al. developed an application with six sessions based on the Dual Processing Cognitive-Emotional Decision-Making Framework [57]. Each session addressed different cognitive and affective content areas via various interactive and tailored activities. Meanwhile, the control group only received an application having six sessions with the contents from Centers for Disease Control and Prevention's HIV Risk Reduction Tool [57]. However, results indicated that intervention group was less likely to report foregoing condoms $(\mathrm{OR}=0.43,95 \%$ CI $0.28-1.44)$ compared to the control group $(\mathrm{p}<0.01)$, while no differences were found in other sexual risk behavior, HIV testing and PrEP uptake between two arms [57]. In contrast, Zhu et al. built a "WeTest"- a WeChat group to provide app-based messages and referrals to health services related to HIV [68]. Using the IMB theory, authors achieved the increase of HIV testing ( $\mathrm{RR}=1.99,95 \% \mathrm{CI} 1.07-3.84)$ and self-testing rate $(\mathrm{RR}=2.17,95 \% \mathrm{CI} 1.08-4.37)$ in the intervention group compared to the control group [68]. Meanwhile, the pre-post trial performed by Sullivan et al. provided a smartphone apps called "HealthMindr", which was built based on the Social Cognitive Theory aiming to facilitate goal setting, self-efficacy, outcome expectations and self-regulation [78]. The authors indicated that $87.1 \%$ used ordered condom, $52.8 \%$ ordered HIV test kits on the app, 77\% tested HIV at least once and 56\% tested multiple times [78].

\section{Study Quality}

In this study, we employed the ICROMS for quality appraisal. The result is presented in Table 2.

For pilot studies, seven pre-post trials had the global quality score ranging from 15 to 26 ( mean $=22$, median $=23$, minimal score requirement $=22$ ), while among ten RCTs, the global quality score ranged from 21 to 30 (mean $=26.7$, median $=27$, minimal score requirement $=22$ ). Two pre-post trials did not meet the minimal score requirement. The reasons included unclear objectives [88] or unclear justification for not having control group [84, 88], no comparison of characteristics between baseline and follow-up [84], not report limitation [84] or ethical approval [84].

For efficacy trials, the global quality score of ten prepost interventions ranged from 15 to 26 (mean $=21.8$, median $=23$, minimal score requirement $=22$ ). Meanwhile, the global quality score of five quasi-experiment studies ranged from 18 to 27 (mean $=22.3$, median $=22$, minimal score requirement $=18$ ). Finally, among RCTs, the global quality score ranged from 15 to 31 (mean $=25.6$, median $=26$, minimal score requirement $=22$ ).

Three studies did not meet the minimal score requirement (one pre-post intervention and two RCTs). In terms of prepost studies, the common reasons included: unclear aims/ objectives [70]; unavailability of clear explanation for the lack of control group and clear description about reliability and validity of measurements; and have potential biases due to the study design [70]. For RCTs, the main reasons comprised: unclear description of randomization approaches 
Table 2 Quality assessment of selected studies using ICROMS

\begin{tabular}{|c|c|c|c|c|c|c|c|c|c|}
\hline Year, author & Study design & $\begin{array}{l}\text { Aims and } \\
\text { Justifica- } \\
\text { tion }\end{array}$ & Sampling & $\begin{array}{l}\text { Outcome } \\
\text { measures }\end{array}$ & Follow-up & $\begin{array}{l}\text { Other } \\
\text { study } \\
\text { aspects }\end{array}$ & $\begin{array}{l}\text { Ana- } \\
\text { lytical } \\
\text { rigor }\end{array}$ & $\begin{array}{l}\text { Other } \\
\text { considera- } \\
\text { tion }\end{array}$ & $\begin{array}{l}\text { Global } \\
\text { Quality } \\
\text { Score }\end{array}$ \\
\hline \multicolumn{10}{|l|}{ Pilot interventions } \\
\hline 2016 Solorio [84] & Pre-post & 2 & 1 & 1 & 1 & 3 & 2 & 5 & 15 \\
\hline 2009 Chiasson [88] & Pre-post & 3 & 1 & 2 & 0 & 3 & 2 & 9 & 19 \\
\hline 2011 Rhodes [73] & Pre-post & 4 & 2 & 1 & 2 & 3 & 2 & 8 & 22 \\
\hline 2018 Fuchs [92] & Pre-post & 4 & 1 & 2 & 2 & 3 & 2 & 9 & 23 \\
\hline 2017 Sullivan [78] & Pre-post & 3 & 2 & 2 & 2 & 4 & 1 & 9 & 23 \\
\hline 2012 Reback [50] & Pre-post & 3 & 2 & 4 & 2 & 4 & 2 & 9 & 26 \\
\hline $\begin{array}{l}\text { 2015 Lelutiu-Weinberger } \\
\text { [59] }\end{array}$ & Pre-post & 5 & 1 & 4 & 2 & 3 & 2 & 9 & 26 \\
\hline 2018 Reiter [85] & RCT & 1 & 3 & 3 & 4 & 0 & 2 & 9 & 22 \\
\hline 2007 Bowen [47] & $\mathrm{RCT}$ & 2 & 4 & 3 & 2 & 2 & 2 & 9 & 24 \\
\hline 2017 Mimiaga [82] & RCT & 2 & 4 & 3 & 6 & 2 & 2 & 7 & 26 \\
\hline 2019 Zhu [68] & $\mathrm{RCT}$ & 2 & 4 & 3 & 6 & 1 & 2 & 8 & 26 \\
\hline 2019 Wray [91] & RCT & 2 & 3 & 3 & 6 & 2 & 2 & 9 & 27 \\
\hline 2019 Bauermeister [57] & RCT & 2 & 4 & 3 & 6 & 2 & 2 & 9 & 28 \\
\hline 2019 Starks [99] & RCT & 2 & 3 & 4 & 6 & 2 & 2 & 9 & 28 \\
\hline 2018 Clark [95] & $\mathrm{RCT}$ & 2 & 4 & 4 & 6 & 2 & 2 & 9 & 29 \\
\hline 2018 McRee [83] & $\mathrm{RCT}$ & 2 & 2 & 3 & 7 & 3 & 3 & 10 & 30 \\
\hline \multicolumn{10}{|l|}{ Efficacy interventions } \\
\hline 2011 Adam [70] & Pre-post & 4 & 1 & 1 & 0 & 3 & 1 & 5 & 15 \\
\hline 2016 Greene [56] & Pre-post & 4 & 1 & 1 & 2 & 3 & 2 & 9 & 22 \\
\hline 2013 Bachmann [79] & Pre-post & 3 & 1 & 2 & 2 & 4 & 2 & 9 & 23 \\
\hline 2014 Kasatpibal [67] & Pre-post & 3 & 1 & 3 & 2 & 3 & 2 & 9 & 23 \\
\hline 2008 Bowen [46] & Pre-post & 6 & 2 & 4 & 2 & 2 & 2 & 8 & 26 \\
\hline 2016 Prati [65] & Quasi-experiment & 2 & 1 & 3 & 0 & 2 & 2 & 8 & 18 \\
\hline 2013 Ko [71] & Quasi-experiment & 2 & 1 & 4 & 1 & 2 & 2 & 9 & 21 \\
\hline 2017 Klein [87] & Quasi-experiment & 2 & 2 & 4 & 0 & 2 & 2 & 9 & 21 \\
\hline 2015 Mi [89] & Quasi-experiment & 2 & 1 & 5 & 2 & 2 & 2 & 9 & 23 \\
\hline 2011 Bourne [66] & Quasi-experiment & 2 & 2 & 5 & 2 & 2 & 2 & 9 & 24 \\
\hline 2015 Mclver [63] & Quasi-experiment & 2 & 2 & 8 & 2 & 2 & 2 & 9 & 27 \\
\hline 2016 Rhodes [72] & RCT & 2 & 0 & 2 & 2 & 2 & 2 & 5 & 15 \\
\hline 2008 Lau [86] & $\mathrm{RCT}$ & 2 & 2 & 2 & 4 & 2 & 2 & 7 & 21 \\
\hline 2010 Carpenter [76] & RCT & 2 & 2 & 2 & 4 & 2 & 2 & 8 & 22 \\
\hline 2010 Rosser [81] & RCT & 2 & 4 & 2 & 6 & 2 & 0 & 7 & 23 \\
\hline $2012 \operatorname{Lin}[61]$ & RCT & 2 & 3 & 3 & 4 & 2 & 0 & 9 & 23 \\
\hline 2016 Fleming [94] & RCT & 2 & 2 & 3 & 4 & 2 & 2 & 9 & 24 \\
\hline 2016 Schonnesson [74] & RCT & 2 & 2 & 3 & 4 & 2 & 2 & 9 & 24 \\
\hline 2016 Noslinger [53] & $\mathrm{RCT}$ & 2 & 4 & 3 & 2 & 2 & 2 & 9 & 24 \\
\hline 2012 Hirshfield [60] & RCT & 2 & 4 & 3 & 3 & 2 & 2 & 9 & 25 \\
\hline 2015 Milam [62] & RCT & 2 & 2 & 4 & 4 & 2 & 2 & 9 & 25 \\
\hline $\begin{array}{l}2019 \text { Hightow-Weidman } \\
\text { [49] }\end{array}$ & RCT & 2 & 3 & 3 & 4 & 2 & 2 & 9 & 25 \\
\hline 2019 Reback [51] & RCT & 2 & 2 & 3 & 6 & 2 & 2 & 9 & 26 \\
\hline 2010 Blas [69] & RCT & 2 & 4 & 3 & 6 & 2 & 2 & 7 & 26 \\
\hline 2015 Young [101] & $\mathrm{RCT}$ & 2 & 4 & 3 & 6 & 2 & 2 & 7 & 26 \\
\hline 2016 Millard [52] & RCT & 2 & 4 & 3 & 4 & 2 & 2 & 9 & 26 \\
\hline 2016 Tang [98] & $\mathrm{RCT}$ & 2 & 2 & 4 & 6 & 2 & 2 & 9 & 27 \\
\hline 2014 Young [100] & RCT & 2 & 2 & 4 & 6 & 2 & 2 & 9 & 27 \\
\hline
\end{tabular}


Table 2 (continued)

\begin{tabular}{|c|c|c|c|c|c|c|c|c|c|}
\hline Year, author & Study design & $\begin{array}{l}\text { Aims and } \\
\text { Justifica- } \\
\text { tion }\end{array}$ & Sampling & $\begin{array}{l}\text { Outcome } \\
\text { measures }\end{array}$ & Follow-up & $\begin{array}{l}\text { Other } \\
\text { study } \\
\text { aspects }\end{array}$ & $\begin{array}{l}\text { Ana- } \\
\text { lytical } \\
\text { rigor }\end{array}$ & $\begin{array}{l}\text { Other } \\
\text { considera- } \\
\text { tion }\end{array}$ & $\begin{array}{l}\text { Global } \\
\text { Quality } \\
\text { Score }\end{array}$ \\
\hline 2016 Fernandez [48] & $\mathrm{RCT}$ & 2 & 4 & 2 & 6 & 2 & 2 & 9 & 27 \\
\hline 2011 Kerani [90] & RCT & 2 & 4 & 6 & 3 & 2 & 2 & 9 & 28 \\
\hline 2013 Christensen [77] & RCT & 2 & 4 & 5 & 4 & 2 & 2 & 9 & 28 \\
\hline 2016 Lau [97] & RCT & 2 & 4 & 3 & 6 & 2 & 2 & 9 & 28 \\
\hline 2017 Wang [80] & RCT & 2 & 4 & 3 & 6 & 2 & 2 & 9 & 28 \\
\hline 2013 Young [102] & $\mathrm{RCT}$ & 2 & 4 & 4 & 6 & 2 & 1 & 9 & 28 \\
\hline 2015 Smith [96] & RCT & 2 & 4 & 5 & 4 & 2 & 2 & 9 & 28 \\
\hline 2018 Cruess [54] & RCT & 2 & 4 & 3 & 6 & 2 & 2 & 9 & 28 \\
\hline 2018 Mustanski [58] & RCT & 2 & 4 & 4 & 6 & 2 & 2 & 9 & 29 \\
\hline 2018 Moore [93] & RCT & 2 & 4 & 5 & 6 & 2 & 2 & 10 & 31 \\
\hline
\end{tabular}

$[72,86]$ and outcome measures $[72,86]$; low retention rates ( $\leq 60 \%)$ [86]; insufficient information about limitations [72] or conclusions $[72,86]$; and had important biases (i.e. introduced bias or selection bias) [72, 86].

\section{Considerations for Sustaining eHealth Interventions}

Table 3 summarizes recommended factors that should be considered in previous trials to enhance the effectiveness of eHealth intervention in MSM population. We categorized these factors into four themes: Technology and system; Content and format; Preparation; and Implementation.

\section{Technology and System}

One suggestion is that integrating the interventions into other existing platforms such as social media sites, chatrooms or forums should be considered to approach a wide MSM population as well as reduce the resources needed for the implementation [73]. In addition, some authors recommended that when developing the intervention, researchers should design in the platform that could adjust to different devices (laptop, tablet, mobile phone, etc.) [62], and involve functions that automatically send messages $[46,63,86]$.

\section{Content and Format}

Many authors emphasized the roles of behavioural theories and individualized/static messages in improving the effectiveness of interventions [52, 53, 55, 59, 62, 69, 79, 86]. Moreover, for the intervention using videos as a main modality, along with the content, the interventionist should test the length of videos in order to optimize the attention of participants [56, 69]. Similarly, although multi-session interventions are acceptable, the length of each session as well as the whole intervention should be piloted to achieve the optimal outcomes [46, 52, 56, 89].
Modes of presentation were also emerged as an important factor in eHealth interventions. For MSM population, some authors recommended that the contents of interventions should be delivered in highly, friendly and engaging interactive ways with the predominance of visual information and real-world style [62, 81]. Multiple modalities as well as diverse intervention messages should be also taken into account $[59,62]$. These approaches could enhance the attention of targeted population; thus, improve the effectiveness of interventions.

\section{Preparation}

The third theme consists of factors related to staff of intervention (or interventionists) and incentives. Some authors suggested that the researchers or interventionists involving in the study should be well-trained in working with as well as developing and carrying tailored messages to MSM [48, 59, 73, 79]. In addition, Bourne et al. noticed that researchers should remember their tasks in sending the MSM reminder because forgetting this action possibly reduce the effectiveness of interventions [66].

In terms of incentives, Schonnesson et al. in Sweden found that incentives did not play a significant role in recruiting participants [74]. Similarly, Bowen et al. indicated that reimbursements had no effect on the retention rate [46]. However, Hirshfield et al. and Hightow-Weidman et al. noted that if there was none of incentives available, the retention rate would be reduced [60]. Therefore, the amount of incentives should be identified clearly before implementation to avoid overspending.

\section{Implementation}

In terms of implementation, three issues should be concerned including recruitment, retention and relationship. The recruitment sources should be varied, especially in 
Table 3 Facilitators and barriers of eHealth interventions in MSM population

\begin{tabular}{|c|c|}
\hline Components & Considerations \\
\hline echnology and system & $\begin{array}{l}\text { Interventions could be implemented within existing technical systems that could reach MSM without burden of enrol- } \\
\text { ment process [73] } \\
\text { Developed on html platform that could not adjust to mobile phone or tablet, reducing the chance to widespread the } \\
\text { intervention to the target population [62] } \\
\text { Electronic delivery system did not operate automatically }[46,86] \text { or the intervention was implemented manually [63], } \\
\text { that could reduce the opportunities to access messages }\end{array}$ \\
\hline \multicolumn{2}{|l|}{ Content and format } \\
\hline Theory and contents & $\begin{array}{l}\text { Combine various behaviour change techniques/theories could increase effects of intervention [52] } \\
\text { Not using individualized messages }[55,59,69,79,86] \text { or static content of messages reduced the effects of intervention } \\
\text { [53,62] } \\
\text { Too short } 69 \text { or too long videos could be a potential barrier [56] }\end{array}$ \\
\hline $\begin{array}{l}\text { Workload and length } \\
\text { of intervention }\end{array}$ & $\begin{array}{l}\text { A multi-session intervention is acceptable and possibly even engaging [46] } \\
\text { Insufficient time for intervention might result in ineffective outcomes [52, 89] } \\
\text { Long-term follow up increased loss to follow up [56] }\end{array}$ \\
\hline Mode of presentation & $\begin{array}{l}\text { Engaging, highly interactive, fun; dominance by visual instead of verbal; written in a real-world direct peer-to-peer } \\
\text { style; allow to compare with other peers }[62,81] \\
\text { Using multiple methods (video, animation, games, etc.) and user-friendly interface allowed for individuals with differ- } \\
\text { ent learning styles to be impacted by the content }[59,62] \\
\text { Participants might not read contents carefully } 86 \text { or become bored with viewing and interacting with the same material } \\
\text { across the intervention [46] } \\
\text { If sessions were boring or not engaging, participant might take more time to complete }[46,62]\end{array}$ \\
\hline \multicolumn{2}{|l|}{ Preparation } \\
\hline Staff & $\begin{array}{l}\text { Interventionist was well trained and a natural helper could gain the trust and respect from participants }[59,73] \\
\text { Developing and informing tailored messages required well-trained providers/interventionists }[48,59,79] \\
\text { Clinicians forgot to send SMS reminder reduced the opportunities to access messages in MSM [66] }\end{array}$ \\
\hline Incentives & $\begin{array}{l}\text { Incentives did not play a role in retention [74], however, no incentives might reduce the retention [60] } \\
\text { Increase reimbursement did not affect retention [46] }\end{array}$ \\
\hline \multicolumn{2}{|l|}{ Implementation } \\
\hline Recruitment & $\begin{array}{l}\text { Place recruitment banner ad on exclusively gay sex sites increased the rate of click compared to on the public service } \\
\text { banners }[74,81,88] \\
\text { Limited recruitment sources might lead to insufficient sample size [74] }\end{array}$ \\
\hline Relationship & $\begin{array}{l}\text { Building rapport increased the level of retention [103] } \\
\text { Promotion of interaction between MSM and facilitators could achieve and sustain an intervention effect and promote } \\
\text { higher retention rates [73] } \\
\text { Lack of interpersonal relationship could lead to be ineffective [86] }\end{array}$ \\
\hline Retention & $\begin{array}{l}\text { Strong retention protocol; interactive engaging activities; appropriate visual learning elements; use realistic sexually } \\
\text { explicit images could increase retention rate }[74,81]\end{array}$ \\
\hline
\end{tabular}

MSM-friendly websites and outreach clinics/organizations, to enrol sufficient sample sizes [74, 81, 88]. For interventions having the interaction between interventionists and MSM, building interpersonal relationships between two sides should be noted, which could facilitate the intervention effect $[73,86,103]$. This factor should be also considered alongside a strong retention protocol and engaging intervention activities and information to improve the high retention rates among participants $[74,81]$.

\section{Discussion}

This systematic review found evidence that eHealth interventions can achieve a decrease in reported risk behaviour for HIV/STI, but no studies included biological testing to enable detecting reduced incidence of HIV or STIs. Fiftyfive studies were found with the predominance of web-based interventions in US-based settings. Most eHealth interventions achieved a short-term behaviour change among participants, however only one intervention could show sustained behaviour change over 12 months. Innovative approaches are needed along with repeated booster of eHealth interventions in order to maintain the intervention effect.

Most eHealth interventions used a 3- or 6-month followup period and achieved behavioural change over this time period. Only four studies were conducted with 12 month follow-ups; and only one of them could maintain the behaviour change over this longer time duration [62, 63, 81]. This drawback might be explained by two reasons: (1) the intervention messages had a little impact on the behaviour change; (2) the washout effect after completing the 
intervention until the follow-up survey [81, 104]. In Rosser et al.'s intervention, the participants completed the intervention in 3 weeks, and after 12 months they performed the final follow-up assessment. During this time period participants might have forgotten the intervention messages that initially caused behaviour change and thereby the effect did not remain at 12 months $[81,104]$. Booster interventions could maintain behaviour change over time, by providing new information as well as delivering the same intervention message to refresh the participants' memory of the intervention concepts and sustain related behaviour change over time [105, 106]. In this review, only two study reported booster interventions in study design [82, 107], of which one pilot trial and one efficacy trial can maintain the behavioral change after 6 months and 12 months, respectively. These findings suggest that further interventions should evaluate the effects of booster interventions on whether they could improve the effectiveness of eHealth interventions in MSM population [53, 108]. Notably, Jacobs et al. expressed concerns about the balance between benefits and costs of eHealth intervention boosters using advanced technical solutions. Careful piloting of the intervention can be helpful to identify the appropriate intensity of intervention messages and boosters to avoid unnecessary costs [109].

Various modalities are employed for eHealth interventions such as website, chat room, social media sites, mobile phone, smartphone applications, email, online video and online virtual simulation. Some studies recommended that successful interventions should contain an interaction component to facilitate the engagement of participants in the intervention rather than only provide information $[46,62$, 81]. Moreover, it may be beneficial to offer the intervention via a diversity of modalities to ease access for participants [59, 62, 107, 109]. Surprisingly, despite the availability of SMS-based interventions using mobile phone, only three pilot studies using smartphone applications as a main modality for the eHealth intervention were implemented and published in the period 2015-2019. Previously, only Wang et al.'s study used the live chat applications as a supplementary mode, which could be used in various devices (smartphone, laptop, tablet, etc.), to help the participants to use HIV self-testing kit [80]. Milam et al. indicated that their platform could not adjust to a tablet and smartphone, and suggested that these devices should be considered in the future interventions [62]. The explosion of smartphone uptake started in 2008, and it is estimated that more than 2.1 billion people globally owned smartphones at the end of 2016 [28, 110]. Smartphone-based interventions have been successful in other behavioural change contexts [111-116]. Recently, several protocols in China [117] or the USA [118-120] have been published to describe the development and use of smartphone applications in behavioral interventions among MSM. Despite the continuity of web-based intervention as the most common mode overtime, our trend analysis underlines an emergence of smartphone applications, SMS/Text messages and Live-chat/Chat room approaches in HIV/STI prevention in the next period. These methods allow real-time monitoring and tailored feedback [28], as well as interactive person-to-person conversations, which are critical for building rapport between interventionists and participants - one of factors for the sustainability of the intervention $[73,86,103]$. Collectively, with the indispensable role of the smartphone in the modern everyday life, developing tailored smartphone applications has a potential effect of promoting sexual health among MSM.

Behavioural theories are widely applied to guide the eHealth interventions, especially Information-MotivationBehaviour and Social Cognitive Theories. Behavioural theories offer mechanisms to guide the study design, sampling, and outcome measurements. Using these theories, along with participants' profiles, could enable researchers to offer tailored and individualized messages, boosting the success of the intervention [52]. Grounding the intervention design in behavioural theories may be more important in eHealth interventions than in real life, as the online intervention cannot compensate for lack in design by providing input by trained staff [121].

In addition to theory and content, length of intervention, mode of presentation and other technical issues could make the eHealth intervention easy to use and thereby increase its effect [122-124]. For example, several studies suggested that the intervention should be integrated with existing infrastructures, developed in platforms that enable participants to access the intervention via various devices, and tested carefully before launching the intervention to ensure usability $[62,73]$. Along with technical aspect, the quality of human resources for the interventions should also be well-prepared. Some studies used a chat-room or other interactive components between an interventionist and participants, and found that well-trained interventionists was required for efficient communication, which included accurate and tailored information to MSM [59, 73]. Furthermore, some studies suggested that along with offering suitable incentives, researchers should build effective partnerships with targeted MSM, which could promote higher retention rates $[60,73]$.

Several methodological issues in existing literature should be noted. Most studies were conducted in the United States, while the remaining other interventions were implemented in Canada, Peru, Australia, Sweden, Belgium, China, Hong Kong, Taiwan and Thailand. This pattern might suggest the unequal distribution of eHealthbased technology among MSM globally [28, 125]. There is a lack of evidence from low and middle-income countries, raising the need to evaluate eHealth interventions in these settings where we see increasing prevalence of HIV/ STI among MSM. Second, some studies had the pre-post 
intervention design without control group, thus decreased the validity of the intervention evaluation. Third, most of the interventions had a small sample size, which limited the inference of the results to a wider population. Moreover, we observed that approximately one-third of selected interventions were pilot trials, and all of them successfully achieved significantly positive outcomes of interest. Meanwhile, all of five interventions where did not obtain any behavioral changes were efficacy trials. This finding implies the matter that pilot interventions are frequently performed with small sample size in limited settings; therefore, the effectiveness of pilot intervention may not be maintained when expanding the intervention to test its efficacy.

This review has several limitations. First, the substantial differences in design and framework among eHealth interventions and evaluation studies make them difficult to synthesize and therefore to perform a meta-analysis was not possible. Second, the systematic search process might not have captured all relevant studies available. We attempted to overcome this by using four databases and in addition screening the reference lists of included studies to find further studies. In spite of these limitations, the review consisted of a large number of interventions that covered different settings and MSM population. Moreover, we have synthesized the facilitators and barriers that could be suggested to improve the substantiality of future eHealth interventions in MSM.

\section{Future Directions}

More eHealth interventions in MSM should be warranted to test the intervention efficacy and determinants of positive effects. To date, eHealth interventions are deemed acceptable in short-term, but more evidence in long-term follow-up are required to confirm the impact of eHealth intervention. In addition, the application of modern technologies such as smart devices should be exploited to deliver the intervention to MSM population. Concerning the quality and the heterogeneity across studies, future studies should pay attention to improve the quality perspectives by using validated checklists such as ICROMS to ensure that important aspects of study design are taken into account. Some components of study design that should be concentrated, including: involving the control group, using well-validate measures to assess primary outcomes, calculating sample size to have sufficient power to detect significances, and well controlling potential biases. Furthermore, technical aspects of intervention emcompass design, content and interface should be carefully evaluated to measure potential differential effects.

\section{Conclusion}

The increasing advance of technology and popularity of the Internet offers unique opportunities to deliver novel eHealth interventions to large populations. This systematic review found data supporting short-term behaviour change by eHealth interventions among MSM. More eHealth intervention strategies among MSM should be evaluated in larger samples with long-term follow-up and booster intervention strategies to promote health among MSM.

Funding We have received no funding for this paper.

\section{Compliance with Ethical Standards}

Conflict of interest The authors declare that they have no conflict of interest.

Ethical Approval This article does not contain any studies with human participants or animals performed by any of the authors.

\section{References}

1. Wilkin T. Primary care for men who have sex with men. N Engl J Med. 2015;373(9):854-62.

2. Mayer KH, Bekker LG, Stall R, Grulich AE, Colfax G, Lama JR. Comprehensive clinical care for men who have sex with men: an integrated approach. Lancet (London, England). 2012;380(9839):378-87.

3. Makadon HJ, Mayer KH, Garofalo R. Optimizing primary care for men who have sex with men. JAMA. 2006;296(19):2362-5.

4. Meyer IH. Prejudice, social stress, and mental health in lesbian, gay, and bisexual populations: conceptual issues and research evidence. Psychol Bull. 2003;129(5):674-97.

5. King M, Semlyen J, Tai SS, et al. A systematic review of mental disorder, suicide, and deliberate self harm in lesbian, gay and bisexual people. BMC Psychiatry. 2008;8:70.

6. Beyrer C, Baral SD, van Griensven F, et al. Global epidemiology of HIV infection in men who have sex with men. Lancet. 2012;380(9839):367-77.

7. de Vries HJ. Sexually transmitted infections in men who have sex with men. Clin Dermatol. 2014;32(2):181-8.

8. Sullivan PS, Jones JS, Baral SD. The global north: HIV epidemiology in high-income countries. Curr Opin HIV AIDS. 2014;9(2):199-205.

9. Okano JT, Robbins D, Palk L, Gerstoft J, Obel N, Blower S. Testing the hypothesis that treatment can eliminate HIV: a nationwide, population-based study of the Danish HIV epidemic in men who have sex with men. Lancet Infect Dis. 2016;16(7):789-96.

10. Rauch A, Rickenbach M, Weber R, et al. Unsafe sex and increased incidence of hepatitis $\mathrm{C}$ virus infection among HIVinfected men who have sex with men: the Swiss HIV Cohort Study. Clin Infect Dis. 2005;41(3):395-402.

11. Boehmer U, Cooley TP, Clark MA. Cancer and men who have sex with men: a systematic review. Lancet Oncol. 2012;13(12):e545-53. 
12. Prevention of hepatitis A through active or passive immunization: Recommendations of the Advisory Committee on Immunization Practices (ACIP). MMWR Recomm Rep. 1999;48(12):1-37.

13. Yaphe S, Bozinoff N, Kyle R, Shivkumar S, Pai NP, Klein M. Incidence of acute hepatitis $C$ virus infection among men who have sex with men with and without HIV infection: a systematic review. Sex Transm Infect. 2012;88(7):558-64.

14. Network TE. EMIS 2010: the European Men-Who-Have-SexWith-Men Internet Survey. Findings from 38 countries. Stockholm: European Centre for Disease Prevention and Control; 2013.

15. Kesler MA, Kaul R, Liu J, et al. Actual sexual risk and perceived risk of HIV acquisition among HIV-negative men who have sex with men in Toronto, Canada. BMC Public Health. 2016;16:254.

16. Friedman MR, Wei C, Klem ML, Silvestre AJ, Markovic N, Stall R. HIV infection and sexual risk among men who have sex with men and women (MSMW): a systematic review and metaanalysis. PLoS ONE. 2014;9(1):e87139.

17. Prah P, Hickson F, Bonell C, et al. Men who have sex with men in Great Britain: comparing methods and estimates from probability and convenience sample surveys. Sex Transm Infect. 2016;92(6):455-63.

18. Bowring AL, Veronese V, Doyle JS, Stoove M, Hellard M. HIV and sexual risk among men who have sex with men and women in Asia: a systematic review and meta-analysis. AIDS Behav. 2016;20(10):2243-65.

19. (MSMGF) TGFoMH. Access to HIV prevention and treatment for men who have sex with men: findings from the 2012 Global Men's Health and Rights Study (GMHR); 2012.

20. Wray TB, Grin B, Dorfman L, et al. Systematic review of interventions to reduce problematic alcohol use in men who have sex with men. Drug Alcohol Rev. 2016;35(2):148-57.

21. Peacock E, Andrinopoulos K, Hembling J. Binge drinking among men who have sex with men and transgender women in San Salvador: correlates and sexual health implications. J Urban Health. 2015;92(4):701-16.

22. Cohen J, Lo YR, Caceres CF, Klausner JD. WHO guidelines for HIV/STI prevention and care among MSM and transgender people: implications for policy and practice. Sex Transm Infect. 2013;89(7):536-8.

23. UNFPA, The Global Forum on MSM and HIV U, UNAIDS, et al. Implementing comprehensive HIV and STI programmes with men who have sex with men: practical guidance for collaborative interventions. New York: United Nations Population Fund; 2015.

24. UNAIDS. Guidance Note: Services for gay men and other men who have sex with men. Geneva: UNAIDS; 2014.

25. World Health Organization. HIV/AIDS among men who have sex with men and transgender populations in South-East Asia: the current situation and national responses. India; 2010.

26. Lorimer K, Kidd L, Lawrence M, McPherson K, Cayless S, Cornish F. Systematic review of reviews of behavioural HIV prevention interventions among men who have sex with men. AIDS Care. 2013;25(2):133-50.

27. Sullivan PS, Carballo-Diéguez A, Coates T, et al. Successes and challenges of HIV prevention in men who have sex with men. Lancet (London, England). 2012;380(9839):388-99.

28. Muessig KE, Nekkanti M, Bauermeister J, Bull S, Hightow-Weidman LB. A systematic review of recent smartphone, Internet and Web 2.0 interventions to address the HIV continuum of care. Curr HIV/AIDS Rep. 2015;12(1):173-90.

29. Sm N. eHealth Applications: Promising Strategies for Behavior Change. New York: Routledge; 2012.

30. Eysenbach G. What is e-health? J Med Internet Res. 2001;3(2):E20.

31. Müller AM, Alley S, Schoeppe S, Vandelanotte C. The effectiveness of e-\& mHealth interventions to promote physical activity and healthy diets in developing countries: a systematic review. Int J Behav Nutr Phys Act. 2016;13(1):109.

32. Oosterveen E, Tzelepis F, Ashton L, Hutchesson MJ. A systematic review of eHealth behavioral interventions targeting smoking, nutrition, alcohol, physical activity and/or obesity for young adults. Prev Med. 2017;99:197-206.

33. Sundström C, Blankers M, Khadjesari Z. Computer-based interventions for problematic alcohol use: a review of systematic reviews. Int J Behav Med. 2016;24(5):646-58.

34. Stromdahl S, Hickson F, Pharris A, Sabido M, Baral S, Thorson A. A systematic review of evidence to inform HIV prevention interventions among men who have sex with men in Europe. Euro Surveill. 2015;20(15):21096.

35. Schnall R, Travers J, Rojas M, Carballo-Diéguez A. eHealth interventions for HIV prevention in high-risk men who have sex with men: a systematic review. J Med Internet Res. 2014;16(5):e134.

36. Noar SM, Willoughby JF. eHealth interventions for HIV prevention. AIDS Care. 2012;24(8):945-52.

37. Henny KD, Wilkes AL, McDonald CM, Denson DJ, Neumann MS. A Rapid Review of eHealth Interventions Addressing the Continuum of HIV Care (2007-2017). AIDS Behav. 2018;22(1):43-63.

38. Catalani C, Philbrick W, Fraser H, Mechael P, Israelski DM. mHealth for HIV treatment \& prevention: a systematic review of the literature. Open AIDS J. 2013;7:17-41.

39. Moher D, Liberati A, Tetzlaff J, Altman DG, Group P. Preferred reporting items for systematic reviews and meta-analyses: the PRISMA statement. Int J Surg. 2010;8(5):336-41.

40. Wa UNDP. Prevention and treatment of HIV and other sexually transmitted infections among men who have sex with men and transgender populations: report of a technical consultation. Geneva: WHO; 2009.

41. European Centre for Disease Prevention and Control. HIV and STI prevention among men who have sex with men. Stockholm: ECDC; 2016.

42. Baral SD, Poteat T, Stromdahl S, Wirtz AL, Guadamuz TE, Beyrer C. Worldwide burden of HIV in transgender women: a systematic review and meta-analysis. Lancet Infect Dis. 2013;13(3):214-22.

43. Sackett DL, Straus SE, Richardson WS, Rosenberg W, Haynes RB. Evidence based medicine: how to practice and teach EBM. New York: Churchill Livingstone; 2000.

44. Zingg W, Castro-Sanchez E, Secci FV, et al. Innovative tools for quality assessment: integrated quality criteria for review of multiple study designs (ICROMS). Public Health. 2016;133:19-37.

45. Sin J, Henderson C, Spain D, Cornelius V, Chen T, Gillard S. eHealth interventions for family carers of people with long term illness: a promising approach? Clin Psychol Rev. 2018;60:109-25.

46. Bowen AM, Williams ML, Daniel CM, Clayton S. Internet based HIV prevention research targeting rural MSM: feasibility, acceptability, and preliminary efficacy. J Behav Med. 2008;31(6):463-77.

47. Bowen AM, Horvath K, Williams ML. A randomized control trial of Internet-delivered HIV prevention targeting rural MSM. Health Educ Res. 2007;22(1):120-7.

48. Fernandez MI, Hosek SG, Hotton AL, et al. A randomized controlled trial of POWER: an Internet-based HIV prevention intervention for black bisexual men. AIDS Behav. 2016;20(9):1951-60.

49. Hightow-Weidman LB, LeGrand S, Muessig KE, et al. A randomized trial of an online risk reduction intervention for young black MSM. AIDS Behav. 2019;23(5):1166-77. 
50. Reback CJ, Grant DL, Fletcher JB, et al. Text messaging reduces HIV risk behaviors among methamphetamine-using men who have sex with men. AIDS Behav. 2012;16(7):1993-2002.

51. Reback CJ, Fletcher JB, Swendeman DA, Metzner M. TheoryBased text-messaging to reduce methamphetamine use and HIV sexual risk behaviors among men who have sex with men: automated unidirectional delivery outperforms bidirectional peer interactive delivery. AIDS Behav. 2019;23(1):37-47.

52. Millard T, Agius PA, McDonald K, Slavin S, Girdler S, Elliott $\mathrm{JH}$. The positive outlook study: a randomised controlled trial evaluating online self-management for HIV positive gay men. AIDS Behav. 2016;20(9):1907-18.

53. Nostlinger C, Platteau T, Bogner J, et al. Computer-assisted intervention for safer sex in HIV-positive men having sex with men: findings of a European randomized multi-center trial. J Acquir Immune Defic Syndr. 2016;71(3):e63-72.

54. Cruess DG, Burnham KE, Finitsis DJ, et al. A randomized clinical trial of a brief internet-based group intervention to reduce sexual transmission risk behavior among HIV-positive gay and bisexual men. Ann Behav Med. 2018;52(2):116-29.

55. Bauermeister JA, Pingel ES, Jadwin-Cakmak L, et al. Acceptability and preliminary efficacy of a tailored online HIV/STI testing intervention for young men who have sex with men: the get connected! program. AIDS Behav. 2015;19(10):1860-74.

56. Greene GJ, Madkins K, Andrews K, Dispenza J, Mustanski B. Implementation and evaluation of the Keep It Up! Online HIV prevention intervention in a community-based setting. AIDS Educ Prev. 2016;28(3):231-45.

57. Bauermeister JA, Tingler RC, Demers M, et al. Acceptability and preliminary efficacy of an online HIV prevention intervention for single young men who have sex with men seeking partners online: the myDEx project. AIDS Behav. 2019. https://doi. org/10.1007/s10461-019-02426-7.

58. Mustanski B, Parsons JT, Sullivan PS, Madkins K, Rosenberg E, Swann G. Biomedical and behavioral outcomes of keep it up! An eHealth HIV Prevention Program RCT. Am J Prev Med. 2018;55(2):151-8.

59. Lelutiu-Weinberger C, Pachankis JE, Gamarel KE, Surace A, Golub SA, Parsons JT. Feasibility, acceptability, and preliminary efficacy of a live-chat social media intervention to reduce HIV risk among young men who have sex with men. AIDS Behav. 2015;19(7):1214-27.

60. Hirshfield S, Chiasson MA, Joseph H, et al. An online randomized controlled trial evaluating HIV prevention digital media interventions for men who have sex with men. PLoS ONE. 2012;7(10):e46252.

61. Lin YJ, Israel T. A computer-based intervention to reduce internalized heterosexism in men. J Counsel Psychol. 2012;59(3):458-64.

62. Milam J, Morris S, Jain S, et al. Randomized controlled trial of an internet application to reduce HIV transmission behavior among HIV infected men who have sex with men. AIDS Behav. 2016;20(6):1173-81.

63. McIver R, Dyda A, McNulty AM, Knight V, Wand HC, Guy RJ. Text message reminders do not improve hepatitis B vaccination rates in an Australian sexual health setting. J Am Med Inf Assoc (JAMIA). 2016;23(e1):e88-92.

64. Rosser BRS, Oakes JM, Konstan J, et al. Reducing HIV risk behavior of men who have sex with men through persuasive computing: results of the Men's INTernet Study-II. AIDS. 2010;24(13):2099-107.

65. Prati G, Mazzoni D, Cicognani E, Albanesi C, Zani B. Evaluating the persuasiveness of an HIV mass communication campaign using gain-framed messages and aimed at creating a superordinate identity. Health Commun. 2016;31(9):1097-104.
66. Bourne C, Knight V, Guy R, Wand H, Lu H, McNulty A. Short message service reminder intervention doubles sexually transmitted infection/HIV re-testing rates among men who have sex with men. Sex Transm Infect. 2011;87(3):229-31.

67. Kasatpibal N, Viseskul N, Srikantha W, Fongkaew W, Surapagdee N, Grimes RM. Effects of Internet-based instruction on HIV-prevention knowledge and practices among men who have sex with men. Nurs Health Sci. 2014;16(4):514-20.

68. Zhu X, Zhang W, Operario D, et al. Effects of a mobile health intervention to promote HIV self-testing with MSM in China: a randomized controlled trial. AIDS Behav. 2019. https://doi. org/10.1007/s10461-019-02452-5.

69. Blas MM, Alva IE, Carcamo CP, et al. Effect of an online videobased intervention to increase HIV testing in men who have sex with men in Peru. PLoS ONE. 2010;5(5):e10448.

70. Adam BD, Murray J, Ross S, Oliver J, Lincoln SG, Rynard V. hivstigma.com, an innovative web-supported stigma reduction intervention for gay and bisexual men. Health Educ Res. 2011;26(5):795-807.

71. Ko N-Y, Hsieh C-H, Wang M-C, et al. Effects of Internet popular opinion leaders (iPOL) among Internet-using men who have sex with men. J Med Internet Res. 2013;15(2):112-20.

72. Rhodes S, McCoy $\mathrm{T}$, Tanner A, et al. Using social media to increase HIV testing among gay and bisexual men, other men who have sex with men, and transgender persons: outcomes from a randomized community trial. Clin Infect Dis. 2016;62(11):1450-3.

73. Rhodes SD, Vissman AT, Stowers J, et al. A CBPR partnership increases HIV testing among men who have sex with men (MSM): outcome findings from a pilot test of the CyBER/testing internet intervention. Health Educ Behav. 2011;38(3):311-20.

74. Schonnesson LN, Bowen AM, Williams ML. Project SMART: preliminary results from a test of the efficacy of a Swedish internet-based HIV risk-reduction intervention for men who have sex with men. Arch Sex Behav. 2016;45(6):1501-11.

75. Baum JL, Barza M. Washout effect vs drug interaction. Arch Ophthalmol. 1977;95(12):2229-30.

76. Carpenter KM, Stoner SA, Mikko AN, Dhanak LP, Parsons JT. Efficacy of a web-based intervention to reduce sexual risk in men who have sex with men. AIDS Behav. 2010;14(3):549-57.

77. Christensen JL, Miller LC, Appleby PR, et al. Reducing shame in a game that predicts HIV risk reduction for young adult MSM: a randomized trial delivered nationally over the Web. J Int AIDS Soc. 2013;16(3 Suppl 2):18716.

78. Sullivan PS, Driggers R, Stekler JD, et al. Usability and acceptability of a mobile comprehensive HIV prevention app for men who have sex with men: a pilot study. JMIR mHealth uHealth. 2017;5(3):e26.

79. Bachmann LH, Grimley DM, Gao H, et al. Impact of a computerassisted, provider-delivered intervention on sexual risk behaviors in HIV-positive men who have sex with men (MSM) in a primary care setting. AIDS Educ Prev. 2013;25(2):87-101.

80. Wang Z, Lau JTF, Ip M, et al. A randomized controlled trial evaluating efficacy of promoting a home-based HIV self-testing with online counseling on increasing hiv testing among men who have sex with men. AIDS Behav. 2017;22(1):190-201.

81. Rosser BR, Oakes JM, Konstan J, et al. Reducing HIV risk behavior of men who have sex with men through persuasive computing: results of the Men's INTernet Study-II. AIDS (London, England). 2010;24(13):2099-107.

82. Mimiaga MJ, Thomas B, Biello K, et al. A pilot randomized controlled trial of an integrated in-person and mobile phone delivered counseling and text messaging intervention to reduce HIV transmission risk among male sex workers in Chennai, India. AIDS Behav. 2017;21(11):3172-81. 
83. McRee AL, Shoben A, Bauermeister JA, Katz ML, Paskett ED, Reiter PL. Outsmart HPV: acceptability and short-term effects of a web-based HPV vaccination intervention for young adult gay and bisexual men. Vaccine. 2018;36(52):8158-64.

84. Solorio R, Norton-Shelpuk P, Forehand M, et al. Tu Amigo Pepe: evaluation of a multi-media marketing campaign that targets young Latino immigrant MSM with HIV testing messages. AIDS Behav. 2016;20(9):1973-88.

85. Reiter PL, Katz ML, Bauermeister JA, Shoben AB, Paskett ED, McRee AL. Increasing human papillomavirus vaccination among young gay and bisexual men: a randomized pilot trial of the outsmart HPV intervention. LGBT Health. 2018;5(5):325-9.

86. Lau JTF, Lau M, Cheung A, Tsui HY. A randomized controlled study to evaluate the efficacy of an internet-based intervention in reducing HIV risk behaviors among men who have sex with men in Hong Kong. AIDS Care. 2008;20(7):820-8.

87. Klein CH, Kuhn T, Huxley D, Kennel J, Withers E, Lomonaco CG. Preliminary findings of a technology-delivered sexual health promotion program for black men who have sex with men: quasi-experimental outcome study. JMIR Public Health Surveill. 2017;3(4):e78.

88. Chiasson MA, Shaw FS, Humberstone M, Hirshfield S, Hartel D. Increased HIV disclosure three months after an online video intervention for men who have sex with men (MSM). AIDS Care. 2009;21(9):1081-9.

89. Mi G, Wu Z, Wang X, et al. Effects of a quasi-randomized webbased intervention on risk behaviors and treatment seeking among HIV-positive men who have sex with men in Chengdu, China. Curr HIV Res. 2017;13(6):490-6.

90. Kerani RP, Fleming M, DeYoung B, Golden MR. A randomized, controlled trial of inSPOT and patient-delivered partner therapy for gonorrhea and chlamydial infection among men who have sex with men. Sex Transm Dis. 2011;38(10):941-6.

91. Wray TB, Kahler CW, Simpanen EM, Operario D. A preliminary randomized controlled trial of game plan, a web application to help men who have sex with Men reduce their HIV risk and alcohol use. AIDS Behav. 2019;23(6):1668-79.

92. Fuchs JD, Stojanovski K, Vittinghoff E, et al. A mobile health strategy to support adherence to antiretroviral preexposure prophylaxis. AIDS Patient Care STDS. 2018;32(3):104-11.

93. Moore DJ, Jain S, Dube MP, et al. Randomized controlled trial of daily text messages to support adherence to preexposure prophylaxis in individuals at risk for human immunodeficiency virus: the TAPIR study. Clin Infect Dis. 2018;66(10):1566-72.

94. Fleming JB, Burns MN. Online evaluative conditioning did not alter internalized homonegativity or self-esteem in gay men. $\mathrm{J}$ Clin Psychol. 2017;73(9):1013-26.

95. Clark JL, Segura ER, Oldenburg CE, et al. Traditional and webbased technologies to improve partner notification following syphilis diagnosis among men who have sex with men in Lima, Peru: Pilot Randomized Controlled Trial. J Med Internet Res. 2018;20(7):e232.

96. Smith KS, Hocking JS, Chen MY, et al. Dual intervention to increase chlamydia retesting: a randomized controlled trial in three populations. Am J Prev Med. 2015;49(1):1-11.

97. Lau JTF, Lee AL, Tse WS, et al. A randomized control trial for evaluating efficacies of two online cognitive interventions with and without fear-appeal imagery approaches in preventing unprotected anal sex among Chinese men who have sex with men. AIDS Behav. 2016;20(9):1851-62.

98. Tang W, Han L, Best J, et al. Crowdsourcing HIV test promotion videos: a noninferiority randomized controlled trial in China. Clin Infect Dis. 2016;62(11):1436-42.

99. Starks TJ, Dellucci TV, Gupta S, et al. A pilot randomized trial of intervention components addressing drug use in couples HIV testing and counseling (CHTC) with male couples. AIDS Behav. 2019. https://doi.org/10.1007/s10461-019-02455-2.

100. Young S, Holloway I, Jaganath D, Rice E, Westmoreland D, Coates T. Project HOPE: online social network changes in an HIV prevention randomized controlled trial for African American and Latino men who have sex with men. Am J Public Health. 2014;104(9):1707-12.

101. Young S, Cumberland W, Nianogo R, Menacho L, Galea J, Coates T. The HOPE social media intervention for global HIV prevention in Peru: a cluster randomised controlled trial. Lancet HIV. 2015;2(1):e27-32.

102. Young SD, Cumberland WG, Lee SJ, Jaganath D, Szekeres G, Coates T. Social networking technologies as an emerging tool for HIV prevention: a cluster randomized trial. Ann Intern Med. 2013;159(5):318-24.

103. Hightow-Weidman LB, Pike E, Fowler B, et al. Healthmpowerment.Org: feasibility and acceptability of delivering an internet intervention to young black men who have sex with men. AIDS Care. 2012;24(7):910-20.

104. Hui D, Zhukovsky DS, Bruera E. Which treatment is better? Ascertaining patient preferences with crossover randomized controlled trials. J Pain Symptom Manage. 2015;49(3):625-31.

105. Whisman MA. The efficacy of booster maintenance sessions in behavior therapy: review and methodological critique. Clin Psychol Rev. 1990;10(2):155-70.

106. Lochman JE, Baden RE, Boxmeyer CL, et al. Does a booster intervention augment the preventive effects of an abbreviated version of the coping power program for aggressive children? J Abnorm Child Psychol. 2014;42(3):367-81.

107. Mustanski B, Garofalo R, Monahan C, Gratzer B, Andrews R. Feasibility, acceptability, and preliminary efficacy of an online HIV prevention program for diverse young men who have sex with men: the keep it up! intervention. AIDS Behav. 2013;17(9):2999-3012.

108. Koblin B, Chesney M, Coates T. Effects of a behavioural intervention to reduce acquisition of HIV infection among men who have sex with men: the EXPLORE randomised controlled study. Lancet (London, England). 2004;364(9428):41-50.

109. Jacobs RJ, Lou JQ, Ownby RL, Caballero J. A systematic review of eHealth interventions to improve health literacy. Health Inf J. 2016;22(2):81-98.

110. Statista. Number of smartphone users worldwide from 2014 to 2020. 2016. https://www.statista.com/statistics/330695/numbe r-of-smartphone-users-worldwide/. Accessed 1 Mar 2017.

111. Mosa ASM, Yoo I, Sheets L. A systematic review of healthcare applications for smartphones. BMC Med Inform Decis Mak. 2012;12:67.

112. Bakker D, Kazantzis N, Rickwood D, Rickard N. Mental health smartphone apps: review and evidence-based recommendations for future developments. JMIR Ment Health. 2016;3(1):e7.

113. Iribarren SJ, Schnall R, Stone PW, Carballo-Diéguez A. Smartphone applications to support tuberculosis prevention and treatment: review and evaluation. JMIR mHealth uHealth. 2016;4(2):e25.

114. Coughlin SS, Whitehead M, Sheats JQ, Mastromonico J, Smith $S$. A review of smartphone applications for promoting physical activity. Jacobs J Community Med. 2016;2(1):021.

115. Buller DB, Borland R, Bettinghaus EP, Shane JH, Zimmerman DE. Randomized trial of a smartphone mobile application compared to text messaging to support smoking cessation. Telemed J e-Health. 2014;20(3):206-14.

116. Meredith SE, Alessi SM, Petry NM. Smartphone applications to reduce alcohol consumption and help patients with alcohol use disorder: a state-of-the-art review. Advanced health care technologies. 2015;1:47-54. 
117. Yan J, Zhang A, Zhou L, Huang Z, Zhang P, Yang G. Development and effectiveness of a mobile phone application conducting health behavioral intervention among men who have sex with men, a randomized controlled trial: study protocol. BMC Public Health. 2017;17(1):355.

118. LeGrand S, Knudtson K, Benkeser D, et al. Testing the efficacy of a social networking gamification app to improve pre-exposure prophylaxis adherence (P3: Prepared, Protected, emPowered): protocol for a randomized controlled trial. JMIR Res Protoc. 2018;7(12):e10448.

119. Liu A, Coleman K, Bojan K, et al. Developing a mobile app (LYNX) to support linkage to HIV/sexually transmitted infection testing and pre-exposure prophylaxis for young men who have sex with men: protocol for a randomized controlled trial. JMIR Res Protoc. 2019;8(1):e10659.

120. Biello KB, Marrow E, Mimiaga MJ, Sullivan P, HightowWeidman L, Mayer KH. A mobile-based app (MyChoices) to increase uptake of HIV testing and pre-exposure prophylaxis by young men who have sex with men: protocol for a pilot randomized controlled trial. JMIR Res Protoc. 2019;8(1):e10694.

121. Pingree S, Hawkins R, Baker T, DuBenske L, Roberts LJ, Gustafson DH. The value of theory for enhancing and understanding e-Health interventions. Am J Prev Med. 2010;38(1):103-9.
122. Wu YP, Steele RG, Connelly MA, Palermo TM, Ritterband LM. Commentary: pediatric eHealth interventions: common challenges during development, implementation, and dissemination. J Pediatr Psychol. 2014;39(6):612-23.

123. van Gemert-Pijnen JE, Nijland N, van Limburg M, et al. A holistic framework to improve the uptake and impact of eHealth technologies. J Med Internet Res. 2011;13(4):e111.

124. Shuvo TA, Islam R, Hossain S, et al. eHealth innovations in LMICs of Africa and Asia: a literature review exploring factors affecting implementation, scale-up, and sustainability. Innov Entrep Health. 2015;2015(2):95-106.

125. Warschauer M, Matuchniak T. New technology and digital worlds: analyzing evidence of equity in access, use, and outcomes. Rev Res Educ. 2010;34(1):179-225.

Publisher's Note Springer Nature remains neutral with regard to jurisdictional claims in published maps and institutional affiliations. 